\title{
Towards zero-waste valorisation of rare-earth-containing industrial process residues: a critical review
}

Koen Binnemans ${ }^{\mathrm{a},{ }^{*}}$, Peter Tom Jones ${ }^{\mathrm{b}}$, Bart Blanpain ${ }^{\mathrm{b}}$, Tom Van Gerven ${ }^{\mathrm{c}}$, Yiannis Pontikes ${ }^{\mathrm{b}}$

${ }^{a}$ KU Leuven, Department of Chemistry, Celestijnenlaan 200F - P.O. box 2404, B-3001 Heverlee (Belgium);

${ }^{\mathrm{b}}$ KU Leuven, Department of Materials Engineering, Kasteelpark Arenberg 44 - P.O. box 2450, B- 3001 Heverlee (Belgium);

${ }^{\mathrm{c}}$ KU Leuven, Department of Chemical Engineering, Willem de Croylaan 46 - P.O. box 2423, B-3001 Heverlee (Belgium).

Reference:

K. Binnemans, P.T. Jones, B. Blanpain, T. Van Gerven, Y. Pontikes Journal of Cleaner Production 99, 17-38 (2015).

* Corresponding author.

Prof. Dr. Koen Binnemans

KU Leuven, Department of Chemistry, Celestijnenlaan 200F - P.O. box 2404, B-3001 Heverlee (Belgium).

E-mail: Koen.Binnemans@chem.kuleuven.be

Phone: +3216327446

Fax: +3216327992 


\begin{abstract}
The supply risk for some critical rare-earth elements (REEs), which are instrumental in many cleantech applications, has sparked the development of innovative recycling schemes for Endof-Life fluorescent lamps, permanent magnets and nickel metal hydride batteries. These waste fractions represent relatively small volumes, albeit with relatively high rare-earth contents. Nevertheless, rare earths are also present in lower concentrations in a multitude of industrial process residues, such as phosphogypsum, bauxite residue (red mud), mine tailings, metallurgical slags, coal ash, incinerator ash and waste water streams. This review discusses the possibilities to recover rare earths from these "secondary resources", which have in common that they contain only low concentrations of rare-earth elements, but are available in very large volumes and could provide significant amounts of rare earths. The success rate is set to increase if the rare-earth recovery from these industrial waste streams is part of a comprehensive, zero-waste, "product-centric" valorisation scheme, in which applications are found for the residual fractions that are obtained after removal of not only the rare earths but also other valuable (base) metals.
\end{abstract}

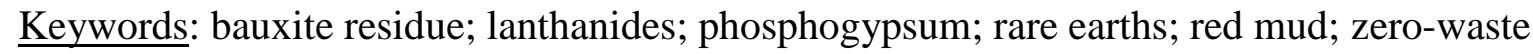
valorisation; metal recovery; mine tailings; slag and ash. 


\section{Introduction}

For more than two decades, at least $95 \%$ of the annual global supply of the rare earths (REEs) has been provided by Chinese rare-earth producers. The tightening of rare-earth export quotas has caused supply risks outside China, as evidenced by the rare-earth crisis of 2011 with record high prices. This situation endangers the secure and sustainable supply of these critical (clean) technology metals, in particular the heavy rare earths, to many economies in the world. Paradoxically, on the positive side, this situation has also stimulated other countries to look for alternative rare-earth resources and to develop their own rare-earth industry. To tackle the rare-earth supply challenge, a threefold approach can be proposed. This strategy is particularly relevant for the heavy rare earths for which the supply risk is far greater than for light rare earths such as lanthanum and cerium. A first component of this strategy is to substitute critical rare earths by less critical metals. Secondly, the supply risk can be mitigated by investing in sustainable primary mining from old or new rare-earth deposits. Mining companies are now actively seeking for new exploitable rare-earth deposits, while old mines are being re-opened. A good example is the Mountain Pass Mine in California, which restarted production in 2012. Nevertheless, many non-Chinese mines, such as the Mountain Pass mine, are mostly light rare earth mines and, hence, do not deliver a meaningful stream of the most critical heavy rare earths. Furthermore, many countries such as Japan and most EU Member States do not possess any type of primary rare-earth deposits on their territory. Consequently, they will have to invest in technospheric mining (Johansson et al., 2013) of secondary rare-earth containing resources in order to obtain a source of both light rare earths and, particularly, heavy rare earths. This is the third component of the strategy.

Technospheric mining, however, can take many forms. With respect to (critical) metal containing streams, such mining incorporates (1) the direct (preconsumer) recycling of metal scrap and swarf generated during the production of metal based (intermediate) products (as 
for instance $\mathrm{NdFeB}$ magnets) and (2) the (postconsumer) recycling and/or urban mining of, respectively, flows and stocks of complex, multi-material, metal-containing products (as for instance a hybrid electric vehicle). (3) landfill mining of historic urban solid waste (Jones et al., 2011), (4) metal recovery from flows of industrial process residues from primary and secondary metal production and, finally, (5) metal recovery from stocks of landfilled industrial process residues, as shown in Figure 1. When considering the potential for rareearth recovery from these five secondary sources, it is clear that at present most attention is going out to the direct recycling of scrap and the recycling/urban mining of End-of-Life rareearth containing products. The state-of-the-art in this domain has been described in detail in recent review papers (Binnemans et al., 2013a; Binnemans and Jones, 2014; Tanaka et al., 2013; Anderson et al., 2013; Innocenzi et al., 2014). The most interesting (heavy) rare earths sources intended for recycling/urban mining are permanent magnets and lamp phosphors (Binnemans et al., 2013a).

In contrast to recycling of rare earths from End-of-Life products, much less attention has been devoted to previously landfilled stocks and freshly produced flows of rare-earthcontaining industrial process residues (Binnemans et al., 2013c) (top part in Figure 1). In general, these secondary resources contain much lower concentrations of rare earths than the End-of-Life consumer goods that are considered for direct recycling or postconsumer recycling/urban mining activities. Nevertheless, the volumes of these residues are enormous so that the total amounts of rare earths locked in these residues are also very large and may secure an independent source of rare earths as well as shield resource-poor countries from export quotas and price fluctuations. This review paper gives on overview of the possibilities to recover rare earths from the most important industrial process residues. These include residues from metal production (as shown in Figure 1) - phosphogypsum, bauxite residue (red mud), mine tailings, metallurgical slags - and industrial process residues from thermal 
treatment facilities (coal ash, incinerator ash). Likewise, it is investigated if waste water streams may be a source of rare-earths as well. In all cases the zero-waste valorisation concept is promoted. For more background on the extractive metallurgy of rare earths, the reader is referred to general references (Gupta and Krishnamurthy, 2004; Gupta and Krishnamurthy, 1992; Habashi, 2013; Xie et al., 2014).

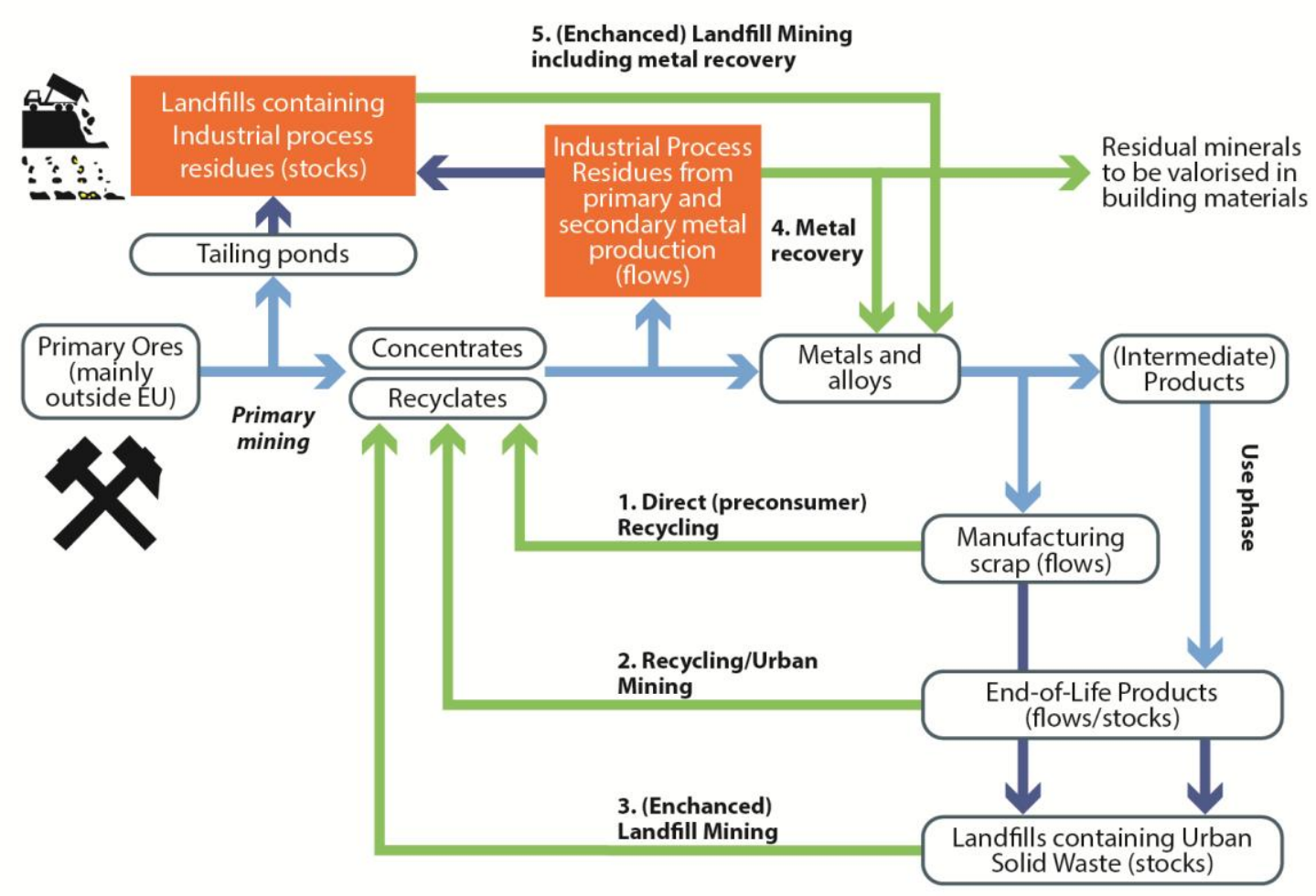

Figure 1: Closing the loop through technospheric mining, revealing the importance of metal recovery from both flows and stocks of industrial process residues from primary and secondary metal production. 


\section{Phosphogypsum}

\subsection{Formation and composition of phosphogypsum}

Phosphogypsum is the main by-product of the production of phosphoric acid $\left(\mathrm{H}_{3} \mathrm{PO}_{4}\right)$ by sulphuric acid $\left(\mathrm{H}_{2} \mathrm{SO}_{4}\right)$ digestion of a concentrated slurry of pulverised phosphate ores (Koopman and Witkamp, 2000). Phosphoric acid is an important raw material for the manufacturing of phosphate fertilisers. Phosphate ores can be divided into two main types according to their origin: sedimentary and igneous phosphate rock (Habashi, 1998). Sedimentary phosphate rock (also known as phosphorite) represents about $85-90 \%$ of the world reserves and is found in Florida, Morocco and the Middle East. Igneous phosphate rock represents the remaining 10-15\% of the world reserves. It is found in the Kola Peninsula (Russia) and Brazil. Phosphate rock varies widely in composition (Becker, 1989). Apatite is the main phosphate mineral in most phosphate deposits (Rutherford et al., 1994). In sedimentary phosphate rock, apatite occurs in an amorphous form: francolite. Francolite has a complex chemical composition and can be represented by the formula $(\mathrm{Ca}, \mathrm{Mg}, \mathrm{Sr}, \mathrm{Na})_{10}\left(\mathrm{PO}_{4}, \mathrm{SO}_{4}, \mathrm{CO}_{3}\right)_{6} \mathrm{~F}_{2-3}$ (Benmore et al., 1983). In igneous phosphate rock, apatite occurs as the variety fluoroapatite, $\mathrm{Ca}_{10}\left(\mathrm{PO}_{4}\right)_{6} \mathrm{~F}_{2}$. Phosphate rock also contains trace amounts of many other elements, including thorium, uranium and rare earths. The rare-earth content depends on the type of phosphate rock (Habashi, 1998; Habashi, 1985) (Table 1). Sedimentary phosphate rock contains $0.01-0.1 \mathrm{wt} \%$ of rare earths, but also about $0.01 \mathrm{wt} \%$ of uranium. Igneous phosphate rock is much richer in rare earths than sedimentary phosphate rock (1-2 wt\%) and contains only very small amounts of uranium. The potential of phosphate rock as a source of rare earths has already been recognised in the 1960s (Anonymous, 1966). Analysis of phosphate rock from Florida gave a total rare-earth content of $0.059 \%$, with the main elements being lanthanum $(0.015 \mathrm{wt} \%)$, cerium $(0.012 \mathrm{wt} \%)$, yttrium $(0.011 \mathrm{wt} \%)$ and neodymium (0.007 wt $\%)$. The scandium concentration was very low: $0.0003 \mathrm{wt} \%$ (3 ppm). It 
was estimated that the 6 million tonnes of phosphate rock that have been processed in the USA in 1964 could have yielded 3,500 tonnes of rare earths (cf. estimated worldwide REO production in 2013: 110,000 tonne (Gambogi, 2014). Cerium, lanthanum and neodymium account for $80 \%$ of the total rare-earth content of phosphate rock (Habashi, 1985).

Table 1. Rare-earth content of phosphate rock. Adapted from (Habashi, 1985).

\begin{tabular}{ll}
\hline Locality & Total rare-earth oxides $(\mathrm{wt} \%)$ \\
\hline Kola (Russia) & $0.8-1.0$ \\
Florida (USA) & $0.06-0.029$ \\
Algeria & $0.13-0.18$ \\
Morocco & $0.14-0.16$ \\
Tunesia & 0.14 \\
Egypt & 0.028 \\
Vietnam & 0.031 \\
\hline
\end{tabular}

The $\mathrm{H}_{2} \mathrm{SO}_{4}$ digestion of fluoroapatite can be represented by the following chemical reaction scheme (Habashi, 1985):

$$
\mathrm{Ca}_{10}\left(\mathrm{PO}_{4}\right)_{6} \mathrm{~F}_{2}+10 \mathrm{H}_{2} \mathrm{SO}_{4}+20 \mathrm{H}_{2} \mathrm{O} \rightarrow 6 \mathrm{H}_{3} \mathrm{PO}_{4}+10 \mathrm{CaSO}_{4} \cdot 2 \mathrm{H}_{2} \mathrm{O} \downarrow+2 \mathrm{HF}
$$

Depending on the production method, the phosphogypsum formed primarily consists of either calcium sulphate dihydrate, $\mathrm{CaSO}_{4} \cdot 2 \mathrm{H}_{2} \mathrm{O}$ (gypsum) or calcium sulphate hemihydrate, $\mathrm{CaSO}_{4} \cdot 1 / 2 \mathrm{H}_{2} \mathrm{O}$, and it contains also small amounts of silica, fluoride compounds and unreacted phosphate rock. The amount of phosphogypsum produced during phosphoric acid production exceeds the mass of the product, i.e. 4.5 to 5.5 tonnes of phosphogypsum are generated per 
tonne of phosphorus pentoxide (El-Didamony et al., 2012). Phosphogypsum is stored in stacks. The stacks form as the slurry containing the by-product phosphogypsum is pumped from the phosphoric acid plant onto a disposal site. The major component of the material in these waste piles is calcium sulphate dihydrate. In Table 2, the average composition of phosphogypsum produced via different processes is shown (Rutherford et al., 1994).

Table 2. Typical elemental composition (wt \%) of phosphogypsum prepared via different processes. Adapted from (Rutherford et al., 1994).

\begin{tabular}{llll}
\hline Component & Dihydrate & Hemihydrate & Hemi-dihydrate \\
\hline $\mathrm{CaO}$ & 32.5 & 36.9 & 32.2 \\
$\mathrm{SO}_{3}$ & 44.0 & 50.3 & 46.5 \\
$\mathrm{P}_{2} \mathrm{O}_{5}$ & 0.65 & 1.50 & 0.25 \\
$\mathrm{~F}$ & 1.2 & 0.8 & 0.5 \\
$\mathrm{SiO}_{2}$ & 0.5 & 0.7 & 0.4 \\
$\mathrm{Fe}_{2} \mathrm{O}_{3}$ & 0.1 & 0.1 & 0.05 \\
$\mathrm{Al}_{2} \mathrm{O}_{3}$ & 0.1 & 0.3 & 0.3 \\
$\mathrm{MgO}$ & 0.1 & - & - \\
$\mathrm{H}_{2} \mathrm{O}$ (crystalline) & 19.0 & 9.0 & 20.0 \\
\hline
\end{tabular}

The rare earths are concentrated in phosphogypsum during the production of phosphoric acid. About 70 to $85 \%$ of the rare earths originally present in the phosphate rock end up in the phosphogypsum. The remainder stays dissolved in the leaching solution, which also contains the phosphoric acid. A smaller part of the rare earths is incorporated in the phosphogypsum if the leaching is performed at lower temperatures or with less concentrated $\mathrm{H}_{2} \mathrm{SO}_{4}$ (Habashi, 1985). The concentrations of the different rare earths in a phosphogypsum sample is shown in 
Table 3 (Germeau et al., 2013).The average concentration of rare earths in phosphogypsum is $0.4 \mathrm{wt} \%$ (Habashi, 1985). This seems to be a very low value compared to the rare-earth content of ore minerals such as bastnäsite, monazite or xenotime. Indeed, the rare-earth deposits that are currently mined have rare-earth oxide (REO) contents between 3 and 15 wt\%. However, the estimated global production of phosphate rock in 2013 was 224 million tonnes (Jasinski, 2014), so that the total amount of rare earths in the mined phosphate rock is also large in absolute terms. This indicates that phosphate rock and the derived product phosphogypsum may become valuable sources of rare earths in the near future, provided the rare-earth prices are high enough. In comparison with red mud (see section 3), phosphogypsum contains lower concentrations of scandium.

Table 3. Concentrations of rare earths in a phosphogypsum sample of the Belgian company Prayon SA, dried at $250^{\circ} \mathrm{C}$ (Germeau et al., 2013).

\begin{tabular}{ll}
\hline Element & Concentration $(\mathrm{ppm})$ \\
\hline $\mathrm{La}$ & 1450 \\
$\mathrm{Ce}$ & 2310 \\
$\mathrm{Pr}$ & 235 \\
$\mathrm{Nd}$ & 899 \\
$\mathrm{Sm}$ & 163 \\
$\mathrm{Eu}$ & 34.9 \\
$\mathrm{Gd}$ & 98.7 \\
$\mathrm{~Tb}$ & 7.45 \\
$\mathrm{Dy}$ & 45.5 \\
$\mathrm{Ho}$ & 7.37 \\
\hline
\end{tabular}




\begin{tabular}{ll}
\hline $\mathrm{Er}$ & 15.7 \\
$\mathrm{Tm}$ & 1.36 \\
$\mathrm{Yb}$ & 5.6 \\
$\mathrm{Lu}$ & 0.568 \\
$\mathrm{Y}$ & 180 \\
$\mathrm{Sc}$ & 1.21 \\
$\mathrm{Total}$ & 5455 \\
\hline
\end{tabular}

\subsection{Recovery of rare earths from phosphogypsum}

About $50 \%$ of the rare earths present in phosphogypsum can be recovered by leaching the phosphogypsum at ambient temperature with a 0.1 to $0.5 \mathrm{M} \mathrm{H}_{2} \mathrm{SO}_{4}$ solution in a solid-toliquid ratio of 1:10 (Habashi, 1985). It is impossible to recover all the rare earths present in phosphogypsum without destruction of the phosphogypsum lattice. The leaching efficiencies can be increased by a gravity flow of the $\mathrm{H}_{2} \mathrm{SO}_{4}$ solution through a column packed with phosphogypsum (Lokshin et al., 2011). Another method for enhanced $\mathrm{H}_{2} \mathrm{SO}_{4}$ leaching is the mechanical activation of phosphogypsum by ball-milling (Todorovsky et al., 1997). The rare earths can be recovered from the leaching solution by precipitation, for instance as sodium rare-earth double sulphates (Lokshin and Tareeva, 2010) or rare-earth hydroxides (Habashi, 1985), or by solvent extraction (Habashi, 1985). In Figure 2, a flow sheet is shown for $\mathrm{H}_{2} \mathrm{SO}_{4}$ attack of phosphate rock, with precipitation of rare-earths as hydroxides (Habashi, 1985). Jarosinki and co-authors described a comprehensive process for the recovery of rare earths from phosphogypsum (Jarosinski et al., 1993) (Figure 3). The three basic steps are: (1) leaching of the rare earths from the phosphogypsum with dilute $\mathrm{H}_{2} \mathrm{SO}_{4}$; (2) concentration of the leachate by evaporation, followed by recovery of the rare earths by solvent extraction with nonyl-phenyl phosphoric acid (NPPA) or by selective precipitation with hydrofluoric acid; 
(3) production of anhydrite $\left(\mathrm{CaSO}_{4}\right)$ from the purified phosphogypsum by recrystallisation in concentrated $\mathrm{H}_{2} \mathrm{SO}_{4}$. Different process parameters had to be used, depending on whether the starting materials were calcium sulphate hemihydrate or dihydrate. The purified anhydrite can be used for production of plaster. Not all rare earths present in phosphate rock end up in phosphogypsum; a part dissolves in the aqueous phosphoric acid solution. The process was tested on a pilot scale, but showed to be too complicated and uneconomical to be industrialised (Wang et al., 2010).

In a two-stage hemihydrate-dihydrate process, calcium sulphate hemihydrate is precipitated and separated from phosphoric acid by filtration in the first step and the hemihydrate is hydrated to the dihydrate in the second step (Zielinski et al., 1993). The second step offers the best conditions for the rare earth recovery because the hydration proceeds via dissolution of hemihydrates salt. This dissolution step brings all rare earths into solution. On the other hand, rare-earth ions in solution inhibit the crystallisation of the dihydrate, so that the rare earths have to be removed from the solution. The rare earths can be recovered from the solution by solvent extraction with a dialkylphosphoric acid, followed by precipitation stripping to form sodium rare-earth double sulphates.

Leveque and Sabot developed a process for the comprehensive recovery of rare earths, uranium and thorium from phosphogypsum. This process consists of a leaching step with $\mathrm{H}_{2} \mathrm{SO}_{4}$, followed by solvent extraction of rare earths, uranium and thorium from the sulphate solution by a mixture of bis(octylphenyl)phosphoric acid and trioctylphosphine oxide (TOPO) (Leveque and Sabot, 1981). By using a mixture of extractants, a synergistic effect was achieved. $\mathrm{H}_{2} \mathrm{SO}_{4}$ was used as leachant, because (1) it showed selectivity towards the dissolution of the targeted metals, (2) it did not change the filterability of the phosphogypsum, (3) the process can be easily integrated in an existing phosphoric production plant, based on 
$\mathrm{H}_{2} \mathrm{SO}_{4}$ attack of phosphate rock. Nevertheless, no evidence of commercialisation of this process was found in the literature.

The Belgian company Prayon SA developed a process for the recovery of rare earths from phosphogypsum (Germeau et al., 2013). Leaching is done by a dilute $\mathrm{H}_{2} \mathrm{SO}_{4}$ solution, while a suspension is stirred at high speeds (up to $6000 \mathrm{rpm}$ ). It is proposed to recover the rare earths from the leachate by solvent extraction or by precipitation with oxalic acid.

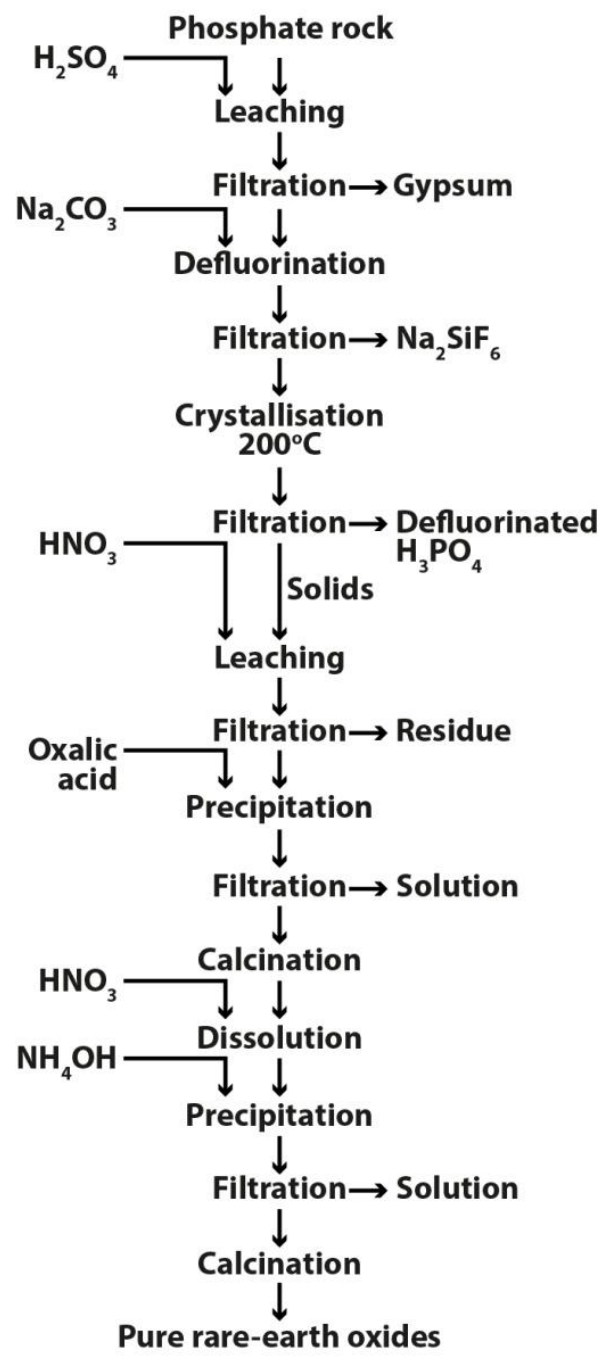


Figure 2. Flow sheet for the attack phosphate rock by $\mathrm{H}_{2} \mathrm{SO}_{4}$, with recovery of rare earths by precipitation as hydroxides. Adapted with permission from (Habashi, 1985). Copyright 1985 Society of Chemical Industry.

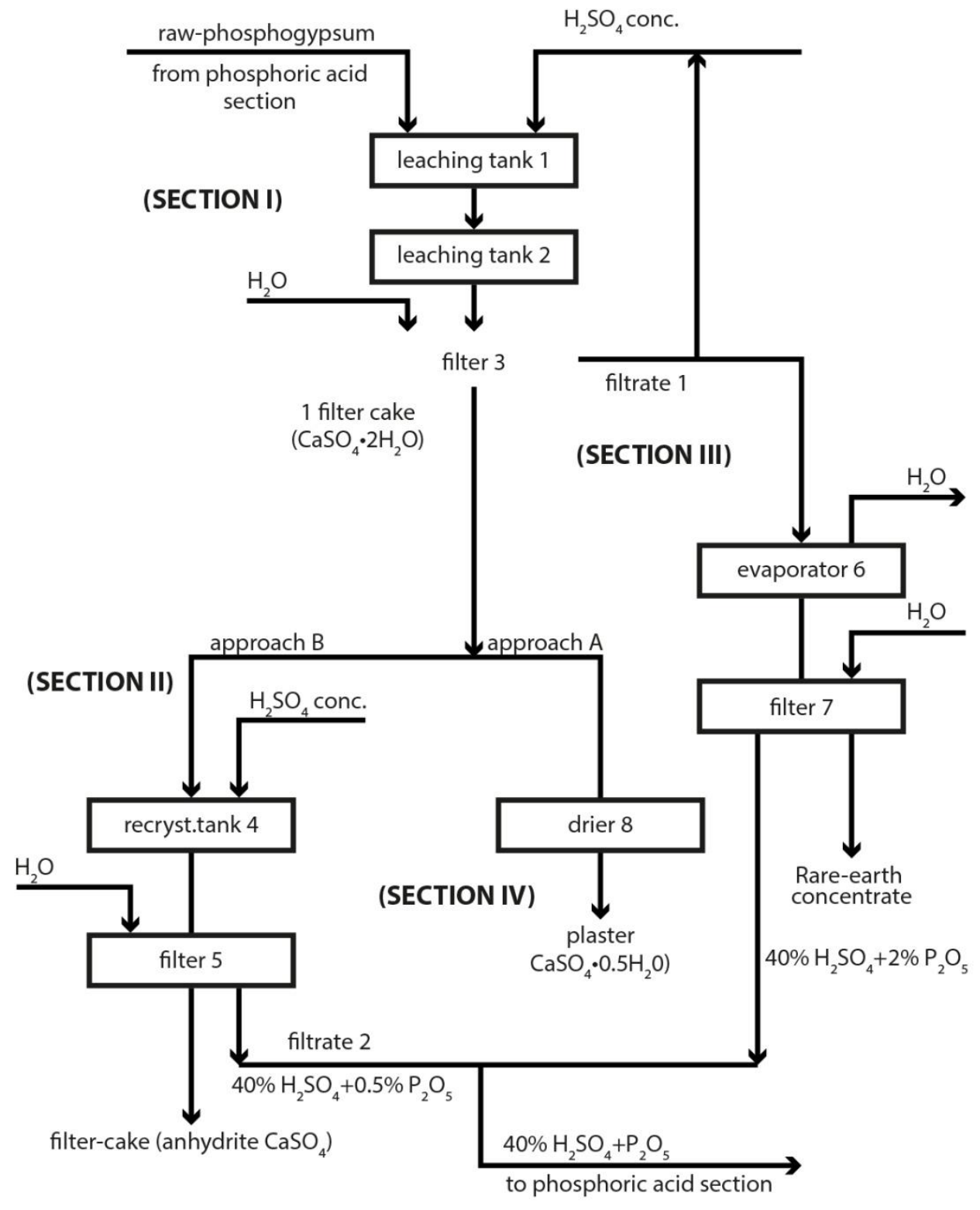


Figure 3. Process for recovery of rare earths from phosphogypsum, with production of purified anhydrite for use as plaster. Adapted with permission from (Jarosinski et al., 1993). Copyright 1993 Published by Elsevier B.V..

Preston and co-workers developed a process to recover rare earths from calcium sulphate sludge derived from the production of phosphoric acid from South-African phosphate rock (Preston and Du, 1998). Higher leaching efficiencies were obtained by leaching with $\mathrm{HNO}_{3}$ instead of $\mathrm{H}_{2} \mathrm{SO}_{4}$, and maximum recovery of rare earths was observed for $3 \mathrm{M} \mathrm{HNO}_{3}$ (Preston et al., 1996a). The recovery markedly decreased with increasing temperatures. Interesting observations were made upon addition of $\mathrm{Ca}\left(\mathrm{NO}_{3}\right)_{2}$ to the $\mathrm{HNO}_{3}$ leachant. Mixtures of $\mathrm{Ca}\left(\mathrm{NO}_{3}\right)_{2}$ and $\mathrm{HNO}_{3}$ were found to be much more effective than solutions of only $\mathrm{HNO}_{3}$. For instance, the treatment of a sludge containing $6.8 \%$ of rare-earth oxides by $1 \mathrm{M} \mathrm{HNO}_{3}$ resulted in $35 \%$ recovery of the rare earths after $72 \mathrm{~h}$, whereas a mixture of $1 \mathrm{M} \mathrm{HNO}_{3}$ and $0.5 \mathrm{M}$ $\mathrm{Ca}\left(\mathrm{NO}_{3}\right)_{2}$ yielded a $76 \%$ recovery under similar conditions. The enhanced leaching was attributed to replacement of the rare-earth ion impurities in the calcium sulphate matrix by calcium ions. An alternative explanation is a lowering effect on the free fluoride ion concentration, which leads to a higher solubility of rare-earth ions. Addition of $\mathrm{Ca}\left(\mathrm{NO}_{3}\right)_{2}$ reduces the $\mathrm{HNO}_{3}$ concentration required for maximum leaching from $3 \mathrm{M}$ to $1 \mathrm{M}$. The dissolved rare-earth ions were recovered from the leach solution by solvent extraction with tributyl phosphate (TBP) or dibutylbutylphosphonate (DBBP) dissolved in xylene. The highest extraction percentages were observed for DBBP. For efficient extraction, the nitrate concentration in the leachate had to be increased by addition of $2.5 \mathrm{M} \mathrm{NH}_{4} \mathrm{NO}_{3}$. By using a higher concentration of $\mathrm{Ca}\left(\mathrm{NO}_{3}\right)_{2}(3 \mathrm{M})$ in the leachant, $\mathrm{NH}_{4} \mathrm{NO}_{3}$ could be omitted, and the DBBP could be replaced by the cheaper TBP. Stripping could be performed by water. Precipitation by oxalic acid and calcination gave a mixed rare-earth oxide. The process was 
further tested by continuous counter-current tests on a lab scale, and also on a pilot-plant scale (Preston et al., 1996a). It was suggested to integrate the process in an existing plant that produces nitrate and phosphate fertilisers, in line with the previous suggestion to redesign the overall process, also upstream. Further research and development led to the invention of three additional processes: (1) a process for the precipitation of high-purity cerium dioxide and the recovery of a heavy rare-earth concentrate (Preston et al., 1996b), (2) a process for the separation of the light ( $\mathrm{La}, \mathrm{Ce}, \mathrm{Pr}, \mathrm{Nd})$ and middle $(\mathrm{Sm}, \mathrm{Eu}, \mathrm{Gd}, \mathrm{Tb})$ rare-earth fractions by solvent extraction with bis(2-ethylhexyl)phosphoric acid (Preston et al., 1996c), and (3) a process for preparation of magnet-grade $(95 \%)$ neodymium oxide from the light rare-earth fraction by extraction with the quaternary ammonium salt Aliquat 336 nitrate (Preston, 1996). $\mathrm{HNO}_{3}$ was found to be a more efficient leachant than $\mathrm{H}_{2} \mathrm{SO}_{4}$ for the recovery of rare earths from hemihydrates phosphogypsum, because of the high solubility of rare-earth phosphates and rare-earth alkali metal double sulphates in $\mathrm{HNO}_{3}$ (Lokshin et al., 2002). Leaching with fresh portions of $\mathrm{HNO}_{3}$ led to a $96 \%$ recovery of the rare earths, while only $7.8 \%$ of the calcium content went into solution. Based on these observations, the authors concluded that the rare earths do not isomorphously co-crystallise with $\mathrm{CaSO}_{4} \cdot 1 / 2 \mathrm{H}_{2} \mathrm{O}$, but rather exist as separate phases. Grinding of the hemihydrates phosphogypsum before leaching with $\mathrm{HNO}_{3}$ led to a higher recovery of rare earths, because the grinding process removed the calcium sulphate crust that covers the surface of the grains of the rare-earth phases. In contrast to what was observed by Preston for leaching of calcium sulphate sludge (Preston et al., 1996a), Lokshin and co-workers did not observe enhanced leaching of hemihydrate phosphogypsum upon addition of $\mathrm{Ca}\left(\mathrm{NO}_{3}\right)_{2}$ to the $\mathrm{HNO}_{3}$ leachant (Lokshin et al., 2002).

Although leaching of metal values from phosphogypsum is typically done by aqueous solutions of mineral acids, it is possible to largely suppress the aqueous phase and to make use of organic solvents. In that case one should use the term "solvometallurgical processing" (or 
"lyometallurgical processing") rather than "hydrometallurgical processing".

Solvometallurgical methods have been invented in the 1950s and early 1960s for the recovery of uranium from low grade complex ores (Grinstead, 1958; Grinstead, 1959b; Grinstead, 1959a; Kruse, 1963; Galvanek, 1959), but unfortunately these methods have been largely neglected ever since, notwithstanding their potential to recover metals from ores and industrial process residues. Two different approaches can be used: solvent leaching and slurry solvent extraction. In solvent leaching, the leaching process is performed with a complexing agent (acting as an extractant) dissolved in an organic solvent. The organic solvent can be miscible or immiscible with water, but it is important that both the extractant and the metal complex are soluble in the solvent. After leaching, the metals can be recovered from the organic phase. In slurry solvent extraction, the finely crushed ore is wetted by a small volume of acid solution, and this slurry is contacted with a water-immiscible organic phase, containing an extractant. This approach is similar to conventional solvent extraction, but the volume of the aqueous phase is significantly reduced. The solvometallurgical processing methods are generic in the sense that they can be applied to a host of different ore types. Besides the largely reduced consumption of acids and a major reduction in the volumes of the leaching solutions, the main advantage is the possibility to achieve a much higher selectivity for metal recovery compared to conventional hydrometallurgical leaching methods. ElDidamony and co-workers investigated the possibility to leach metals from phosphogypsum with organic extraction agents dissolved in kerosene (El-Didamony et al., 2012). Although the main aim of this study was the removal of radionuclides from phosphogypsum, the experimental results also indicated that this method was applicable to recover the rare earths. The best results were observed for leaching of phosphogypsum with tributylphosphate (TBP) dissolved in kerosene. This treatment removed $69.8 \%$ of the rare earths present in the solid material. The method was improved by using mixtures of TBP and TOPO $(\mathrm{TOPO}=$ 
trioctylphosphine oxide) in kerosene instead of pure TBP mixtures. In this case the recovery of the rare earths equalled 80\% (EI-Didamony et al., 2013).

\subsection{Leaching of phosphate rock by nitric acid or hydrochloric acid}

Instead of using $\mathrm{H}_{2} \mathrm{SO}_{4}$, phosphate rock can also be treated by $\mathrm{HNO}_{3}$ or $\mathrm{HCl}$. In contrast to leaching with $\mathrm{H}_{2} \mathrm{SO}_{4}$ no solid residues comparable to phosphogypsum are created by leaching with $\mathrm{HNO}_{3}$ or $\mathrm{HCl}$, although still some solid residues will be formed. When phosphate rock is leached with a $\mathrm{HNO}_{3}$ solution, all rare earths are solubilised as nitrates (Habashi, 1985). Phosphate rock, with the exception of silicate gangue material, is readily soluble in $50-60 \% \mathrm{HNO}_{3}$ at $60{ }^{\circ} \mathrm{C}$ :

$$
\mathrm{Ca}_{10}\left(\mathrm{PO}_{4}\right)_{6} \mathrm{~F}_{2}+20 \mathrm{HNO}_{3} \rightarrow 6 \mathrm{H}_{3} \mathrm{PO}_{4}+10 \mathrm{Ca}\left(\mathrm{NO}_{3}\right)_{2}+2 \mathrm{HF}
$$

After dissolution of the phosphates, the slurry has to be filtered to remove silica. The solution is cooled to $-5{ }^{\circ} \mathrm{C}$ to induce crystallisation of $\mathrm{Ca}\left(\mathrm{NO}_{3}\right)_{2} \cdot 4 \mathrm{H}_{2} \mathrm{O}$, which is removed from the solution by centrifugation. The solution can be defluorinated by addition of $\mathrm{NaNO}_{3}$ to precipitate $\mathrm{Na}_{2} \mathrm{SiF}_{6}$. The rare earths can be recovered by adjusting the $\mathrm{pH}$ to $0.3-1.4$ with ammonia, resulting in the formation of a phosphate precipitate containing 80 to $100 \%$ of the rare earths (Habashi, 1985). Another method to recover the rare earths is to extract them with tributylphosphate (TPB) (Werner et al., 1966a; Werner et al., 1966b), but this solvent extraction step should be done before crystallisation of $\mathrm{Ca}\left(\mathrm{NO}_{3}\right)_{2} \cdot 4 \mathrm{H}_{2} \mathrm{O}$, since the calcium ions enhance the extraction. After extraction, the rare-earths can be removed from the organic phase by stripping with water, followed by precipitation as hydroxides by addition of ammonia to the water phase. Uranium is also extracted by TBP. Selectivity can be obtained by $\mathrm{pH}$ control: uranium is extracted at very low $\mathrm{pH}$ values $(0.6-0.7)$ and the extraction efficiency drops at higher $\mathrm{pH}$ values, whereas maximum recovery of rare earths can be 
achieved at a pH of 1.0 where a precipitate starts to form (Habashi et al., 1986). Uranium can be extracted from the solution together with $\mathrm{H}_{3} \mathrm{PO}_{4}$ by tertiary amyl alcohol and can be stripped by a $50 \% \mathrm{NH}_{4} \mathrm{NO}_{3}$ solution (Habashi and Awadalla, 1986). The co-extracted $\mathrm{H}_{3} \mathrm{PO}_{4}$ may be stripped with $\mathrm{NH}_{3}$. The rare earths, left behind in the leachate solution, can be extracted by TBP. A flow sheet for the treatment of phosphate rock with $\mathrm{HNO}_{3}$ and the recovery of the rare earths from the chloride solution is shown in Figure 4.

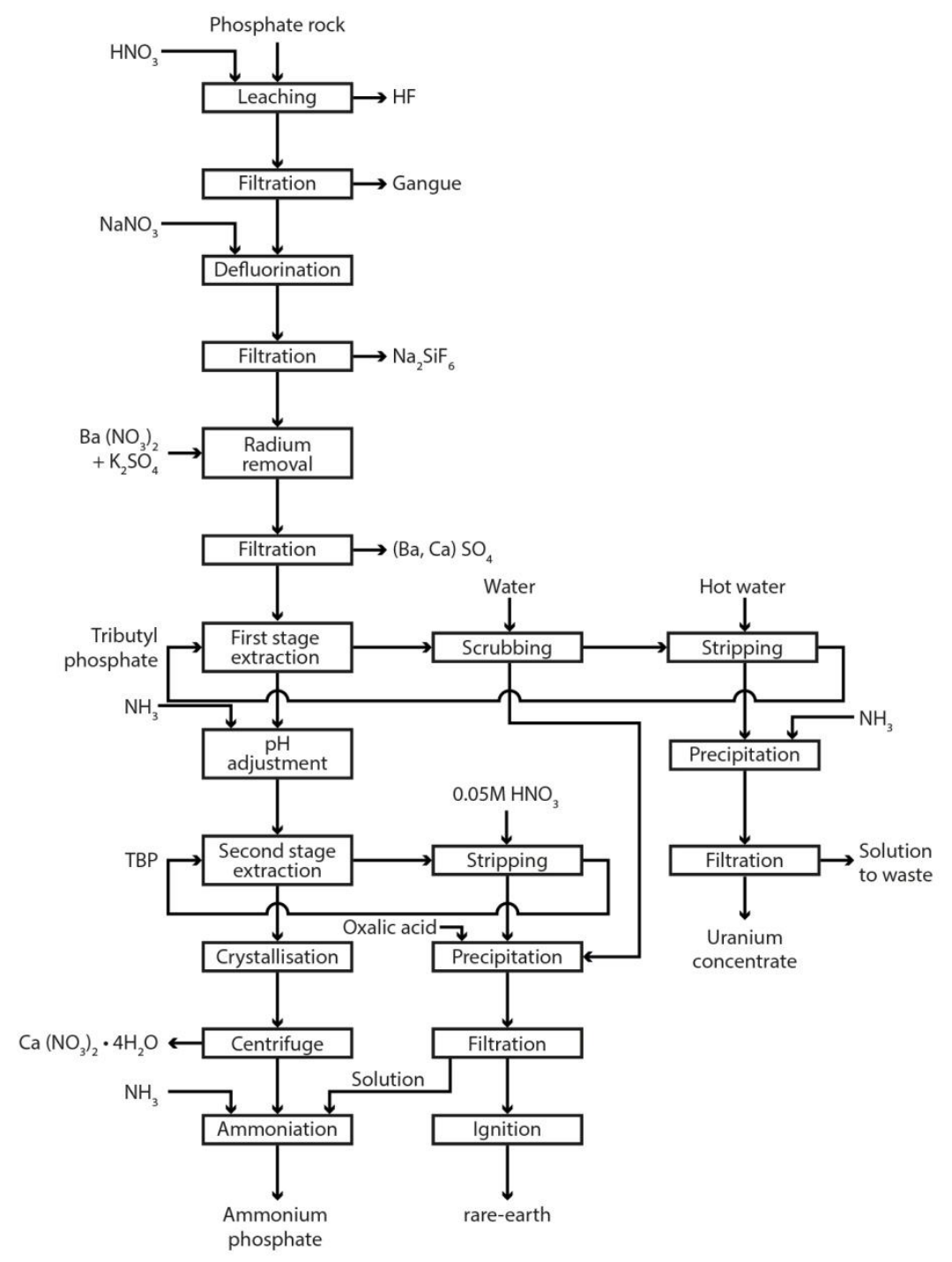

Figure 4. Proposed flow sheet for the treatment of phosphate rock with $\mathrm{HNO}_{3}$, with recovery of rare earths. Adapted with permission from (Habashi et al., 1986). Copyright 1986 Society of Chemical Industry. 
The $\mathrm{HCl}$ route has received less attention than the $\mathrm{HNO}_{3}$ route. Just as in the case of $\mathrm{HNO}_{3}$, digestion of phosphate rock with $\mathrm{HCl}$ will bring all the solid material in solution, with the exception of silicate gangue material (Habashi et al., 1987):

$$
\mathrm{Ca}_{10}\left(\mathrm{PO}_{4}\right)_{6} \mathrm{~F}_{2}+20 \mathrm{HCl} \rightarrow 6 \mathrm{H}_{3} \mathrm{PO}_{4}+10 \mathrm{CaCl}_{2}+2 \mathrm{HF}
$$

A flow sheet for the treatment of phosphate rock by $\mathrm{HCl}$ and the recovery of the rare earths from the chloride solution can be found in Figure 5. The phosphate rock is leached with a stoichiometric amount of $\mathrm{HCl}$ at $40{ }^{\circ} \mathrm{C}$. Addition of $\mathrm{NaCl}$ to the leachate will cause removal of fluorine by precipitation of $\mathrm{Na}_{2} \mathrm{SiF}_{6}$. Radium can be removed from the solution by coprecipitation with $\mathrm{BaSO}_{4}$ upon consecutive addition of $\mathrm{BaCl}_{2}$ and $\mathrm{Na}_{2} \mathrm{SO}_{4}$. Uranium can be removed by solvent extraction with a dilute solution (5\%) of TBP in an aliphatic diluent. $\mathrm{H}_{3} \mathrm{PO}_{4}$ is separated from $\mathrm{CaCl}_{2}$ by solvent extraction with TBP. Stripping of $\mathrm{H}_{3} \mathrm{PO}_{4}$ from the organic phase by ammonia gives ammonium phosphate fertiliser. $\mathrm{The} \mathrm{CaCl}_{2}$ in the aqueous solution can be precipitated as gypsum by addition of $\mathrm{H}_{2} \mathrm{SO}_{4}$. In this way, $\mathrm{HCl}$ is reformed. In contrast to phosphogypsum, the gypsum formed by precipitation with $\mathrm{H}_{2} \mathrm{SO}_{4}$ from chloride solution is not radioactive. The rare-earth elements can be recovered from the solution by precipitation as phosphates by partial neutralisation of the acidic solution by $\mathrm{Ca}(\mathrm{OH})_{2}$. Alternatively, the rare earths can be recovered from the solution as hydroxides by precipitation with ammonia, before gypsum is precipitated. The recovery of the rare earths by this process is about $60 \%$. Attack of phosphate rock by $\mathrm{HCl}$ was recommended because it facilitates the recovery of rare earths compared to attack by $\mathrm{H}_{2} \mathrm{SO}_{4}$ (Shlewit, 2011). 


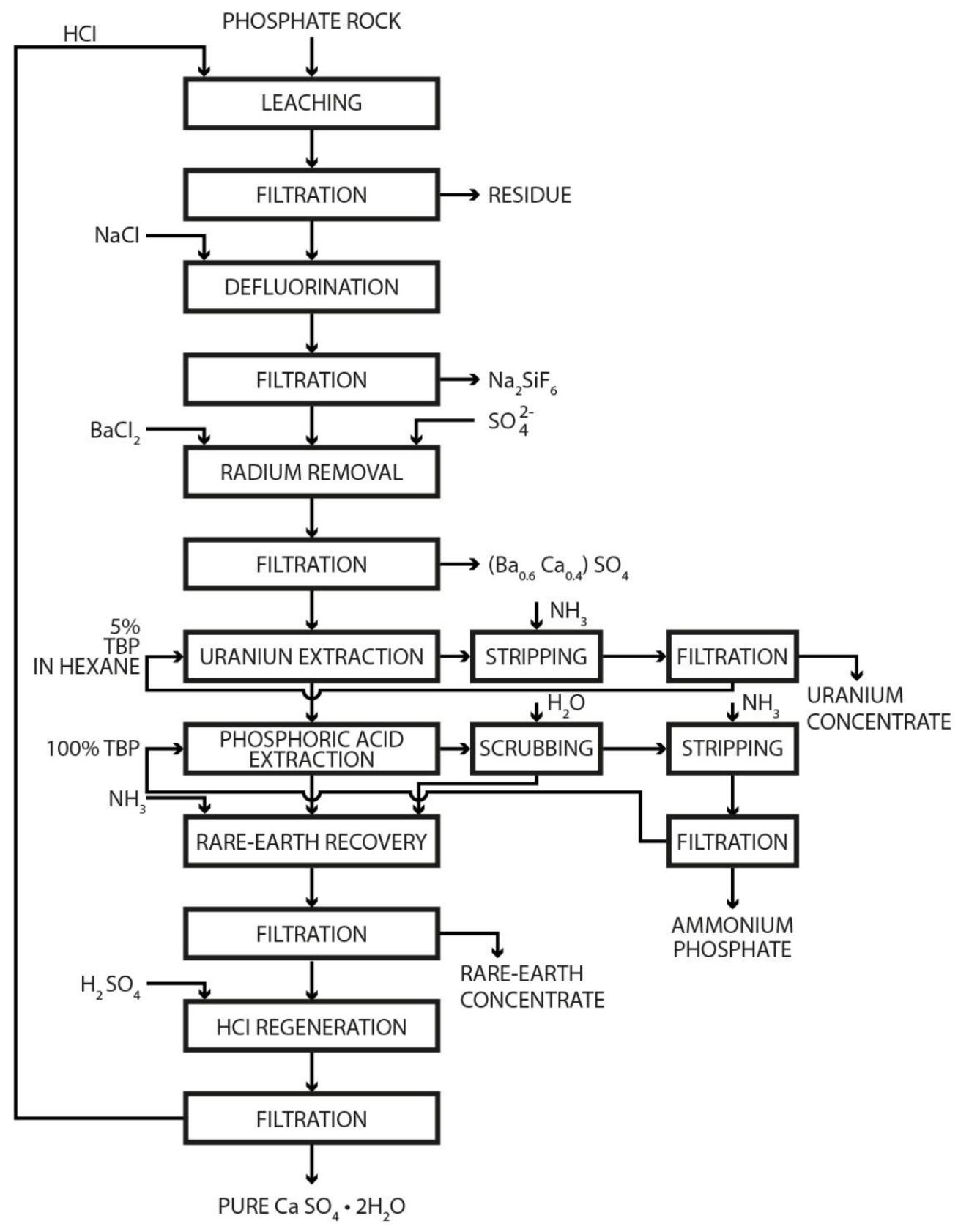

Figure 5. Proposed flow sheet for the treatment of phosphate rock with $\mathrm{HCl}$, with recovery of rare earths. Adapted with permission from (Habashi et al., 1987). Copyright 1987 Society of Chemical Industry. 
Habashi proposed in situ, dump or vat leaching of phosphate rocks with dilute $\mathrm{HNO}_{3}$ $(20 \%)$ or $\mathrm{HCl}(10 \%)$ to get a solution of monocalcium phosphate, and to allow recovering uranium and rare earths (Habashi and Awadalla, 1988; Habashi, 1989; Habashi, 1994). The rare earths can be recovered from the nitrate leach solution at the natural $\mathrm{pH}$ of the leach solution by TBP and from the chloride leach solution by bis(2-ethylhexyl)phosphoric acid . Evaporation of the leach solution leads to formation of the double salts $\mathrm{CaClH}_{2} \mathrm{PO}_{4} \cdot \mathrm{H}_{2} \mathrm{O}$ or $\mathrm{Ca}\left(\mathrm{NO}_{3}\right) \mathrm{H}_{2} \mathrm{PO}_{4} \cdot \mathrm{H}_{2} \mathrm{O}$. The double salts can be decomposed at $200-250{ }^{\circ} \mathrm{C}$ to $\mathrm{CaHPO}_{4}$. Advantages of this process include (1) low capital costs, (2) elimination of the phosphogypsum problem, (3) enhanced possibility to recover rare earths, uranium and fluorine, and (4) enhanced possibility to control the radium content of the phosphate rock.

Phosphogypsum can be decomposed by reaction with ammonium carbonate, so that ammonium sulphate fertiliser and calcium carbonate are formed (Habashi, 1985; Burnett et al., 1996):

$$
\mathrm{CaSO}_{4} \cdot 2 \mathrm{H}_{2} \mathrm{O}+\left(\mathrm{NH}_{4}\right)_{2} \mathrm{CO}_{3} \rightarrow\left(\mathrm{NH}_{4}\right)_{2} \mathrm{SO}_{4}+\mathrm{CaCO}_{3} \downarrow+2 \mathrm{H}_{2} \mathrm{O}
$$

The rare earths report to $\mathrm{CaCO}_{3}$ and can be recovered by dissolution of $\mathrm{CaCO}_{3}$ in $\mathrm{HNO}_{3}$, followed by removal of the rare earths by solvent extraction (Habashi, 1985). Alternatively, $\mathrm{CaCO}_{3}$ can be calcined to $\mathrm{CaO}$ and this compound can be dissolved by leaching with an $\mathrm{NH}_{4} \mathrm{Cl}$ solution. This results in a rare-earth rich residue.

\subsection{Recovery of rare earths from phosphoric acid}

Phosphoric acid produced by $\mathrm{H}_{2} \mathrm{SO}_{4}$ leaching contains about $1 \mathrm{~g} \mathrm{~L}^{-1}$ of rare earths. This is only 15 to $30 \%$ of the rare earths originally present in the phosphate rock, since most of the rare earths report to the phosphogypsum. This is in contrast to uranium that largely reports to 
the phosphoric acid solution (Bunus, 2000). Many researchers have investigated the possibility to recover rare earths and uranium from these phosphoric acid leaching solutions, and most of these methods were based on solvent extraction or ion-exchange (Kumar et al., 2011; Radhika et al., 2011; Kumar et al., 2010; Reddy et al., 2009; Bunus and Dumitrescu, 1992; Bunus et al., 1994; Bunus, 2000; Koopman et al., 1999b; Koopman et al., 1999a; Habashi, 1985). Lower temperatures, higher concentrations of phosphoric acid and larger liquid-to-solid ratios increase the rare-earth concentration in the phosphoric acid leach solution (Wang et al., 2010). Addition of surfactants enhances the growth of gypsum crystals and improves the leaching of rare earths (Wang et al., 2010). Non-equilibrium extraction via centrifugal contacting was able to increase the separation factor between rare earths and iron more than 250 times (Wang et al., 2011a).

\section{Bauxite residue (red mud)}

\subsection{Formation and composition of bauxite residue}

Bauxite, a mixture of impure hydrated aluminium oxides, is the most important aluminium ore. The estimated global production of bauxite in 2013 was 259 million tonnes (Bray, 2014). There are different classification schemes for bauxites, depending on their origin (Patterson et al., 1986). An often used method of classification divides the bauxites into laterite and karst types. The laterite-type bauxite deposits are the very large blanket deposits formed mainly by surficial weathering in tropical regions, and these bauxites are mostly lying on top of aluminosilicate rocks. The karst-type deposits are found on top of carbonate rocks. Lateric bauxites (about $88 \%$ of the global reserves) are found in Suriname, Guyana, Venezuela, Brazil, Guinea, India, Indonesia, Vietnam, Australia and the USA. Karstic bauxites (about $12 \%$ of the global reserves) are mainly found in Europe (Greece, France, 
Hungary, Romania), Jamaica, Russia and China. Karstic-type bauxites are richer in rare earths compared to lateritic bauxite. Depending on the type of deposit, the principal aluminiumbearing components are $\mathrm{Al}(\mathrm{OH})_{3}$ (gibbsite), $\gamma-\mathrm{AlO}(\mathrm{OH})$ (boehmite) and $\alpha-\mathrm{AlO}(\mathrm{OH})$ (diaspore). Lateritic bauxites contain mainly gibbsite, whereas the karstic bauxites are rich in boehmite and diaspore. The chemical composition of representative bauxites is given in Table 4. Aluminium metal is produced from pure $\mathrm{Al}_{2} \mathrm{O}_{3}$, which is obtained via the Bayer process, where bauxite is digested in a concentrated $\mathrm{NaOH}$ solution at temperatures and pressures. This digestion in $\mathrm{NaOH}$ converts the aluminium minerals to sodium aluminate, which is soluble in the $\mathrm{NaOH}$ solution due to the amphoteric character of aluminium. The other components of bauxite do not dissolve or are converted to sparsely soluble compounds. The solution, which is rich in dissolved $\mathrm{Al}_{2} \mathrm{O}_{3}$, is separated from the bauxite residue (BR), more commonly known as red mud (Jones and Haynes, 2011; Power et al., 2011; Klauber et al., 2011; Grafe et al., 2011; Grafe and Klauber, 2011). In the translated Russian literature, the term "red sludge" is used. The $\mathrm{pH}$ of the wet red mud slurry varies between 9.7 and 12.9, with an average of 11.3 (Grafe et al., 2011). The bauxite residue composition depends on the type of bauxite and the process parameters of the Bayer process (Table 5) (Grafe et al., 2011). Bauxite residue has a complex mineralogy (Table 6). In Table 7, the main chemical components of different bauxite residues are given. Worldwide there is an annual bauxite residue production of $1.2 \times 10^{8}$ tonnes (dry matter) and a total inventory of $3 \times 10^{9}$ tonnes, stored in huge tailing ponds (International Aluminium Institute, 2013). These tailing ponds carry risks, as revealed in 2010 by the dam failure of the Ajka refinery in Hungary and the resulting loss of human lives and environmental catastrophe (Ruyters et al., 2011; Gelencser et al., 2011). 
Table 4. Chemical compositions of typical bauxites (in wt\%). Adapted from (Patterson et al., 1986).

\begin{tabular}{llllll}
\hline Origin & $\mathrm{Al}_{2} \mathrm{O}_{3}$ & $\mathrm{SiO}_{2}$ & $\mathrm{Fe}_{2} \mathrm{O}_{3}$ & $\mathrm{TiO}_{2}$ & Loss on \\
& & & & & ignition \\
\hline Australia & 54.8 & $3.4-4.2$ & 17.1 & 3.4 & 26.4 \\
Brazil & 55.9 & 4.8 & 9.4 & 1.3 & 28.6 \\
France & 53.0 & 7.8 & 21.4 & 2.6 & 13.3 \\
Ghana & 51.6 & 1.3 & 17.4 & 1.9 & 13.3 \\
Greece & 57.6 & 3.0 & 22.8 & 2.75 & 12.17 \\
Guyana & $55-61$ & $1-10$ & $0.8-5$ & $2-5$ & $30-35$ \\
Jamaica & $49.1-50.6$ & $0.7-6.1$ & $18.9-20.5$ & $2.5-2.7$ & $24.6-27.3$ \\
Suriname & $58.5-60.0$ & $3.4-4.3$ & $2.7-4.4$ & $2.4-2.7$ & $30.7-31.4$ \\
Arkansas (USA) & $45-50$ & 13 & 8 & $2.5-3$ & 25 \\
\hline
\end{tabular}

Table 5. Process parameters of the Bayer process (Grafe et al., 2011).

\begin{tabular}{lll}
\hline & Gibbsite-rich bauxite & Boehmite-rich bauxite \\
\hline Temperature $\left({ }^{\circ} \mathrm{C}\right)$ & $104-145$ & $200-232$ \\
Pressure $(\mathrm{atm})$ & $1.0-3.0$ & 6.0 \\
Concentration $\mathrm{NaOH}(\mathrm{M})$ & $3.6-8.9$ & $3.6-5.0$ \\
\hline
\end{tabular}


Table 6. Mineralogical composition of bauxite residues. Adapted from (Grafe et al., 2011)

\begin{tabular}{lll}
\hline Mineral & Chemical formula & Range (wt\%) \\
\hline Hematite & $\alpha-\mathrm{Fe}_{2} \mathrm{O}_{3}$ & $7-29$ \\
Goethite & $\alpha-\mathrm{FeOOH}$ & $7.3-24.3$ \\
Magnetite & $\mathrm{Fe}_{3} \mathrm{O}_{4}$ & $0-8$ \\
Diaspore & $\alpha-\mathrm{AlOOH}$ & $0.5-0.6$ \\
Boehmite & $\gamma-\mathrm{AlOOH}$ & $1-9.6$ \\
Gibbsite & $\mathrm{Al}\left(\mathrm{OH}_{3}\right.$ & $1-5$ \\
Quartz & $\mathrm{SiO}_{2}$ & $1.2-4.9$ \\
Rutile & $\mathrm{TiO}_{2}$ & $1.1-5.4$ \\
Anatase & $\mathrm{TiO}_{2}$ & $0.3-5$ \\
Sodalite & $\mathrm{Na}_{8}\left[\mathrm{Al}_{6} \mathrm{Si}_{6} \mathrm{O}_{24}\right]\left[(\mathrm{OH})_{2}\right]$ & $2.7-24$ \\
Cancrinite & $\mathrm{Na}_{6}\left[\mathrm{Al}_{6} \mathrm{Si}_{6} \mathrm{O}_{24}\right] \cdot 2 \mathrm{CaCO}_{3}$ & $0-51$ \\
Calcite & $\mathrm{CaCO}_{3}$ & $1-11.2$ \\
Perovskite & $\mathrm{CaTiO}_{3}$ & $0-11.5$ \\
\hline
\end{tabular}


Table 7. Elemental compositions of bauxites residues (wt\%) Adapted from reference (Grafe et al., 2011).

\begin{tabular}{llllllll}
\hline Bauxite & Refinery & $\mathrm{Al}_{2} \mathrm{O}_{3}$ & $\mathrm{Fe}_{2} \mathrm{O}_{3}$ & $\mathrm{SiO}_{2}$ & $\mathrm{TiO}_{2}$ & $\mathrm{CaO}$ & $\mathrm{Na}_{2} \mathrm{O}$ \\
Origin & & & & & & \\
\hline Greece & Aluminium & 15.6 & 42.5 & 9.2 & 5.9 & 19.7 & 2.4 \\
& de Greece & & & & & & \\
Hungary & Ajka & 14.8 & 42.1 & 13.5 & 5.2 & 6.1 & 8.2 \\
Turkey & Seydisehir & 20.24 & 39.84 & 15.27 & 4.15 & 1.8 & 9.43 \\
China & Shandong & 6.9 & 12.8 & 19.1 & 3.43 & 46.0 & 2.37 \\
China & Shanxi & 7.3 & 6.8 & 13.9 & 2.5 & 33.9 & 2.7 \\
India & Renukoot & 21.9 & 28.1 & 7.5 & 15.6 & 10.2 & 4.5 \\
India & Korba & 19.4 & 27.9 & 7.3 & 16.4 & 11.8 & 3.3 \\
India & Damanjodi & 14.5 & 54.8 & 6.4 & 3.7 & 2.5 & 4.8 \\
Australia & Pinjarra & 17.1 & 36.2 & 23.8 & 3.9 & 3.9 & 1.6 \\
Jamaica & Kirkvine & 13.2 & 49.4 & 3.0 & 7.3 & 9.4 & 4.0 \\
Guinea & Aughinish & 23.6 & 30.4 & 9.65 & 17.85 & 6.4 & 5.3 \\
Ghana & Burntisland & 23.43 & 36.31 & 18.25 & 5.97 & 4.38 & 12.36 \\
\hline & & & & & & & \\
\hline
\end{tabular}

\subsection{Recovery of rare earths from red mud}

All rare earths end up in the bauxite residue during the processing of bauxite by the Bayer process, because these elements are associated with iron and titanium minerals that remain unchanged (Derevyankin et al., 1981c). The enrichment factor of the rare earths in bauxite residue compared to bauxite is about a factor of two (Table 8) (OchsenkühnPetropoulou et al., 1994). The average concentration of rare earths in bauxite from the 
Parnassos-Ghiona mountains in Greece is $506 \mathrm{ppm}$, whereas the average concentration of the resulting bauxite residue is 1040 ppm (Ochsenkühn-Petropoulou et al., 1994). It must be mentioned that Greek bauxite is often mixed with tropical bauxites during its processing to alumina. The rare-earth concentration in Jamaican red mud varies between 1500 and 2500 ppm (Wagh and Pinnock, 1987). Bauxite residue is rich in scandium: bauxite residue from Greece contains about 130 ppm of scandium, whereas bauxite residue produced from Jamaican bauxite contains up to 390 ppm (Wagh and Pinnock, 1987). However, the highest rare-earth concentrations can be found in the bauxite residue produced from bauxites from Moengo in Suriname, with scandium concentrations as high as $1700 \mathrm{ppm}$ (Logomerac, 1971), while Russian bauxite residue was reported to contain 135 ppm of $\mathrm{Sc}_{2} \mathrm{O}_{3}$ (Fomin et al., 2004). These scandium concentrations are much higher than the average abundance of 22 ppm of scandium in the Earth's crust, and point to a significant enrichment of scandium in bauxite and bauxite residue. Although minerals with a high scandium content do exist (e.g. thortveitite and kolbeckite), they only form very small deposits (Wang et al., 2011b). The lack of rich scandium deposits hampers the widespread use of scandium, although scandium could find useful applications as an alloying metal for aluminium (Royset and Ryum, 2005) and as a recyclable Lewis acid catalyst for the production of fine chemicals (Kobayashi, 1999). It can be expected that the demand of scandium will be increasing in the near future, due to the increasing need of scandium for preparing scandium-stabilised zirconia used in solid oxide fuel cells (Badwal et al., 2000). For these reasons, the recovery of scandium from red mud could be of high economic interest (Petrakova et al., 2014). Scandium represents more than $95 \%$ of the economic value of rare earths in red mud. Every alumina plant with a capacity of more than 1 million tonnes of $\mathrm{Al}_{2} \mathrm{O}_{3}$ has the potential of producing 150 tonnes of scandium or more (Yatsenko and Pyagai, 2010). However, very little information is available on the mineralogy of the rare-earth-rich phases in red mud. Allanite-(La) and dissakisite-(Ce) were 
identified as the rare-earth phases in an Indian bauxite residue sample, containing $70 \mathrm{ppm}$ of lanthanum and 100 ppm of cerium (Abhilash et al., 2014).

Table 8. Average concentration of rare earths in Greek bauxites and bauxite residues, and the enrichment factor of rare earths in bauxite residue. Adapted from reference (OchsenkühnPetropoulou et al., 1994). The values are expressed in ppm (g/tonne).

\begin{tabular}{llll}
\hline Element & Bauxite & Bauxite residue & Enrichment factor \\
\hline $\mathrm{La}$ & 87.2 & 149.0 & 1.78 \\
$\mathrm{Ce}$ & 224.3 & 418.0 & 1.87 \\
$\mathrm{Pr}$ & 13.9 & 25.8 & 2.13 \\
$\mathrm{Nd}$ & 62.4 & 115.0 & 1.99 \\
$\mathrm{Sm}$ & 13.2 & 28.9 & 2.30 \\
$\mathrm{Eu}$ & 2.5 & 5.0 & 1.89 \\
$\mathrm{Gd}$ & 12.8 & 23.3 & 1.86 \\
$\mathrm{~Tb}$ & n.d. & n.d & n.d. \\
$\mathrm{Dy}$ & 7.0 & 12.8 & 2.15 \\
$\mathrm{Ho}$ & 2.0 & 4.3 & 2.15 \\
$\mathrm{Er}$ & 8.1 & 17.2 & 2.15 \\
$\mathrm{Tm}$ & n.d. & n.d. & n.d. \\
$\mathrm{Yb}$ & 8.0 & 15.6 & 1.99 \\
$\mathrm{Lu}$ & 1.4 & 2.4 & 1.76 \\
$\mathrm{Y}$ & 55.9 & 93.9 & 1.68 \\
$\mathrm{Sc}$ & 59.0 & 127.9 & 2.17 \\
\hline
\end{tabular}


There are numerous studies on the extraction of rare earths, and of scandium in particular, from bauxite residue. The two main approaches are either purely hydrometallurgical flow sheets or a combination of pyrometallurgical and hydrometallurgical processes (Wang et al., 2011b). The purpose of the hydrometallurgical processes is to selectively leach the minor metals from bauxite residue. It has been an important discovery that the rare earths are readily leachable from bauxite residue by diluted mineral acids, whereas majority elements such as iron cannot be leached from bauxite under the same experimental conditions (Fulford et al., 1991a). A comparative study of leaching with different acids $\left(\mathrm{HCl}, \mathrm{HNO}_{3}\right.$ or $\left.\mathrm{H}_{2} \mathrm{SO}_{4}\right)$, has shown that $0.5 \mathrm{M} \mathrm{HNO}_{3}$ is the best leachant and that the leaching process can be performed at ambient temperatures and pressures (Ochsenkühn-Petropoulou et al., 1996). 80\% of scandium and $96 \%$ of yttrium could be recovered, but the leaching procedure was less efficient for the light lanthanides (30 to 50\% recovery). The leaching process with dilute $\mathrm{HNO}_{3}$ has been performed at a pilot scale and optimised for the recovery of scandium from bauxite residue (Ochsenkühn-Petropoulou et al., 2002) (Figure 6). An issue related to leaching with $\mathrm{HNO}_{3}$ is the difficulty to recover nitrate ions adsorbed to bauxite residue (Petrakova et al., 2014). Flushing with an excess of water create large volumes of waste water contaminated by nitrate ions. Removal of nitrate ions from waste water is difficult since most nitrate salts are water soluble, so that nitrates cannot be precipitated. An analytical method based on reverse-phase HPLC was developed for the determination and quantification of rare earths from red mud (Tsakanika et al., 2004). Dilute $\mathrm{H}_{2} \mathrm{SO}_{4}$ is the most efficient leachant for leaching of scandium from Australian bauxite residue (Wang et al., 2013), in contrast to leaching of scandium from Greek bauxite residue. This difference in leaching behaviour was attributed to the differences in mineralogical composition of these two types of bauxite residue (Wang et al., 2013). Subsequent tests to recover scandium from the leachate were not done on real samples but rather on synthetic 
ones prepared by dissolution of rare-earth sulphate salts. Scandium could be extracted from the leachate by a mixture of bis(2-ethylhexyl)phosphoric acid (D2EPHA) and tributylphosphate (TBP) at $\mathrm{pH} 0.4$, with hardly any co-extraction of iron. The authors proposed a conceptual flow sheet for the recovery of $\mathrm{Sc}_{2} \mathrm{O}_{3}$ from bauxite residue (Figure 7). Leaching with $\mathrm{HCl}$ is very efficient for recovery of rare earths, but a main disadvantage of this method is that large amounts of iron are codissolved (Borra et al., 2015).

$\mathrm{H}_{2} \mathrm{SO}_{4}$ leaching studies on Indian bauxite residue sample containing $70 \mathrm{ppm}$ of lanthanum and $110 \mathrm{ppm}$ of cerium showed that maximum recovery was obtained with a 3M $\mathrm{H}_{2} \mathrm{SO}_{4}$ solution (Abhilash et al., 2014). However, while maximum recovery of lanthanum was achieved at $35{ }^{\circ} \mathrm{C}$, the maximum recovery of cerium occurred at $75^{\circ} \mathrm{C}$. It must be realised that upon leaching of bauxite residue with acids, part of the acid is consumed for neutralisation of the highly alkaline bauxite residue. After leaching, the rare earths can be recovered from the leachate by selective precipitation as oxalate, or by solvent extraction. Different ion-exchange resins have been tested to selectively take up scandium from the leachate after leaching bauxite residue with $\mathrm{H}_{2} \mathrm{SO}_{4}$ (Smirnov and Molchanova, 1997). Scandium could be eluted from the loaded resin by a $\mathrm{Na}_{2} \mathrm{CO}_{3}$ solution and scandium was precipitated as $\mathrm{Sc}(\mathrm{OH})_{3}$ from the concentrated eluate by addition of $\mathrm{NaOH}$ solution. The literature data show that the acid leaching results strongly depend on the type of bauxite residue, because the mineralogical composition of the bauxite residue determines which acid is best suited for leaching. Therefore, a recovery process for rare earths from bauxite residue needs to be tailored for a given type of bauxite residue. For instance, results obtained for experiments on Greek bauxite residue samples are not necessarily applicable to Australian bauxite residue. The close association of scandium with iron minerals is evident from the correlation between the dissolution of iron and the recovery of scandium (Borra et al., 2015). About $50 \%$ of the scandium in bauxite residue samples can be recovered without bringing too 
much iron into solution. However, trying to recover more than $50 \%$ of the scandium does inevitably result in dissolution of a major part of the iron. It is not be possible to recover $100 \%$ of the scandium present in the bauxite residue without dissolving all of the iron.

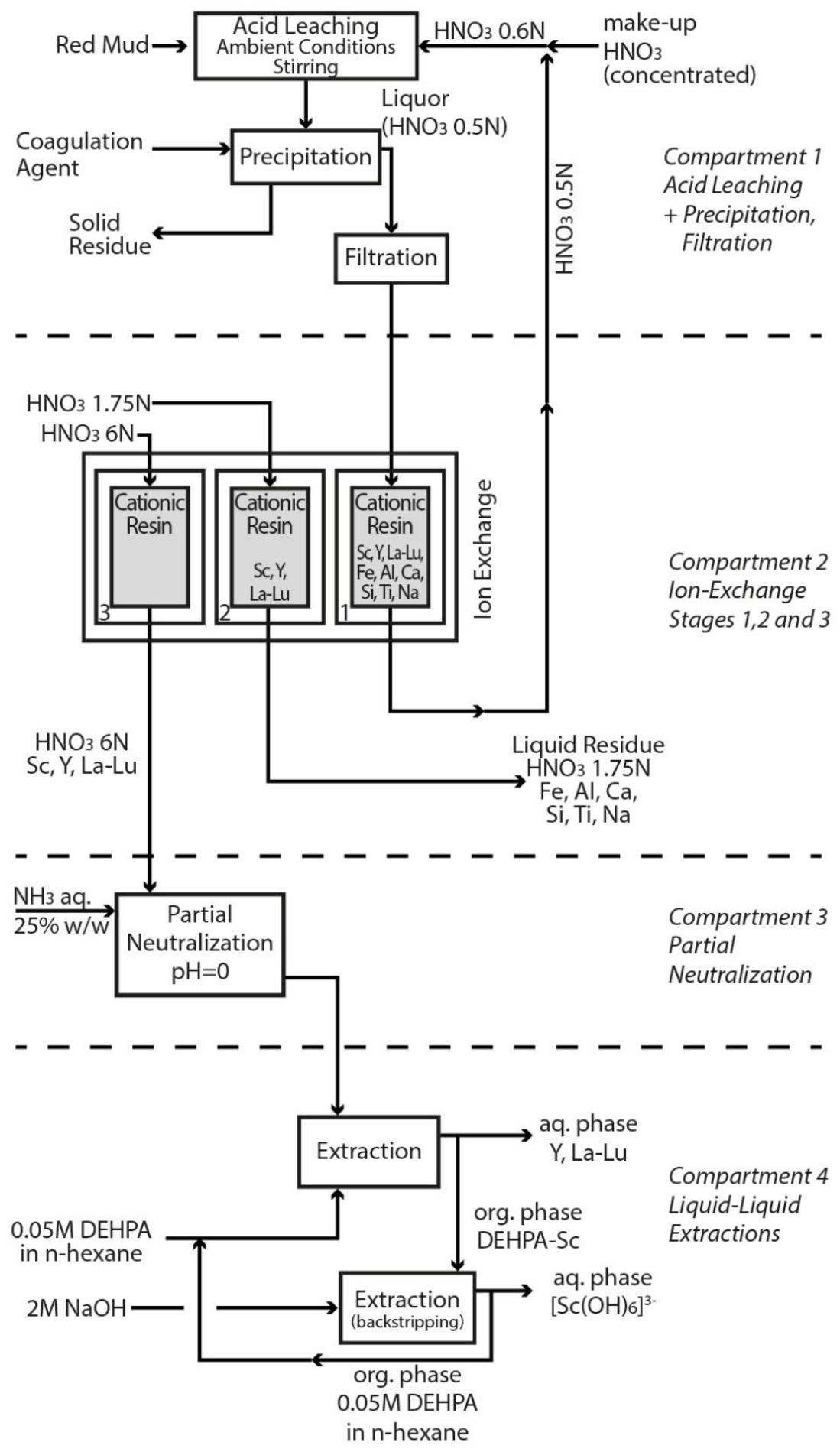


Figure 6. Conceptual flow sheet for the recovery of scandium from bauxite residue by a $\mathrm{HNO}_{3}$ leaching method. Adapted with permission from (Ochsenkühn-Petropoulou et al., 2002). Copyright 2002 American Chemical Society.

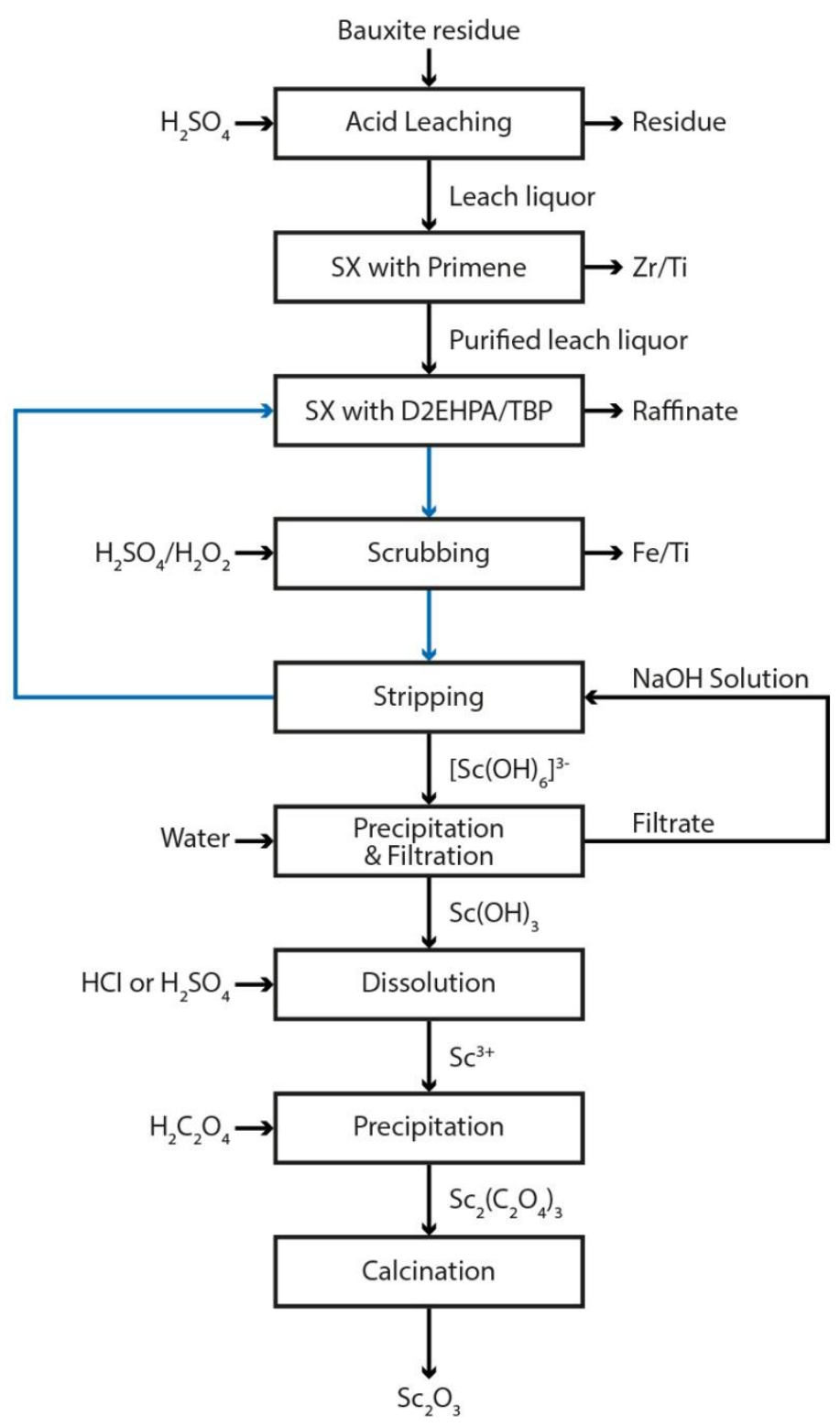


Figure 7. Conceptual flow sheet for the recovery of scandium from bauxite residue by a $\mathrm{H}_{2} \mathrm{SO}_{4}$ leaching method. Adapted with permission from (Wang et al., 2013). Copyright 2013 Elsevier B.V..

The rare earths can be selectively dissolved by digesting bauxite residue with a dilute acid solution made by saturating water with $\mathrm{SO}_{2}$ (forming sulphurous acid), leaving most of the iron undissolved (Fulford et al., 1991a; Fulford et al., 1991b; Kuwabara et al., 1967). Also sodium, aluminium and silicon present in the form of sodalite are brought into solution. The rare earths can be recovered by solvent extraction. In the Canadian Orbite process, bauxite residue is leached with a concentrated $\mathrm{HCl}$ solution in an autoclave at temperatures between 125 and $150{ }^{\circ} \mathrm{C}$ (Boudreault et al., 2013b) (Figure 8). This brings aluminium, iron and the rare earths into solution. By saturating the leachate with $\mathrm{HCl}$, it is possible to induce crystallisation of $\mathrm{AlCl}_{3} \cdot 6 \mathrm{H}_{2} \mathrm{O}$. Solid $\mathrm{AlCl}_{3} \cdot 6 \mathrm{H}_{2} \mathrm{O}$ is separated from the solution and converted by calcinations to $\mathrm{Al}_{2} \mathrm{O}_{3}$, with recovery of $\mathrm{HCl}$ gas. The remaining solution is concentrated and $\mathrm{FeCl}_{3}$ is hydrolysed to $\mathrm{Fe}_{2} \mathrm{O}_{3}$ (hematite) between 155 to $170{ }^{\circ} \mathrm{C}$. After removal of $\mathrm{Fe}_{2} \mathrm{O}_{3}$ a solution of rare earths is obtained, from which the rare earths can be recovered by solvent extraction. A main issue of a process based on $\mathrm{HCl}$ is the highly corrosive character of $\mathrm{HCl}$ gas and $\mathrm{HCl}$ solutions. In 2013 the Japanese company Nippon Light Metals has set up pilot plant studies on the grounds of the Jamaica Bauxite Institute (JBI) in Hope Gardens, St. Andrew (Jamaica) to extract rare earths and especially scandium from bauxite residue (Richardson, 2013). Technical information on this Japanese process is not available. In a recent review, leaching with $\mathrm{H}_{2} \mathrm{SO}_{4}$ is considered to the economically most efficient method for recovery of rare earths from bauxite residue (Petrakova et al., 2014). 


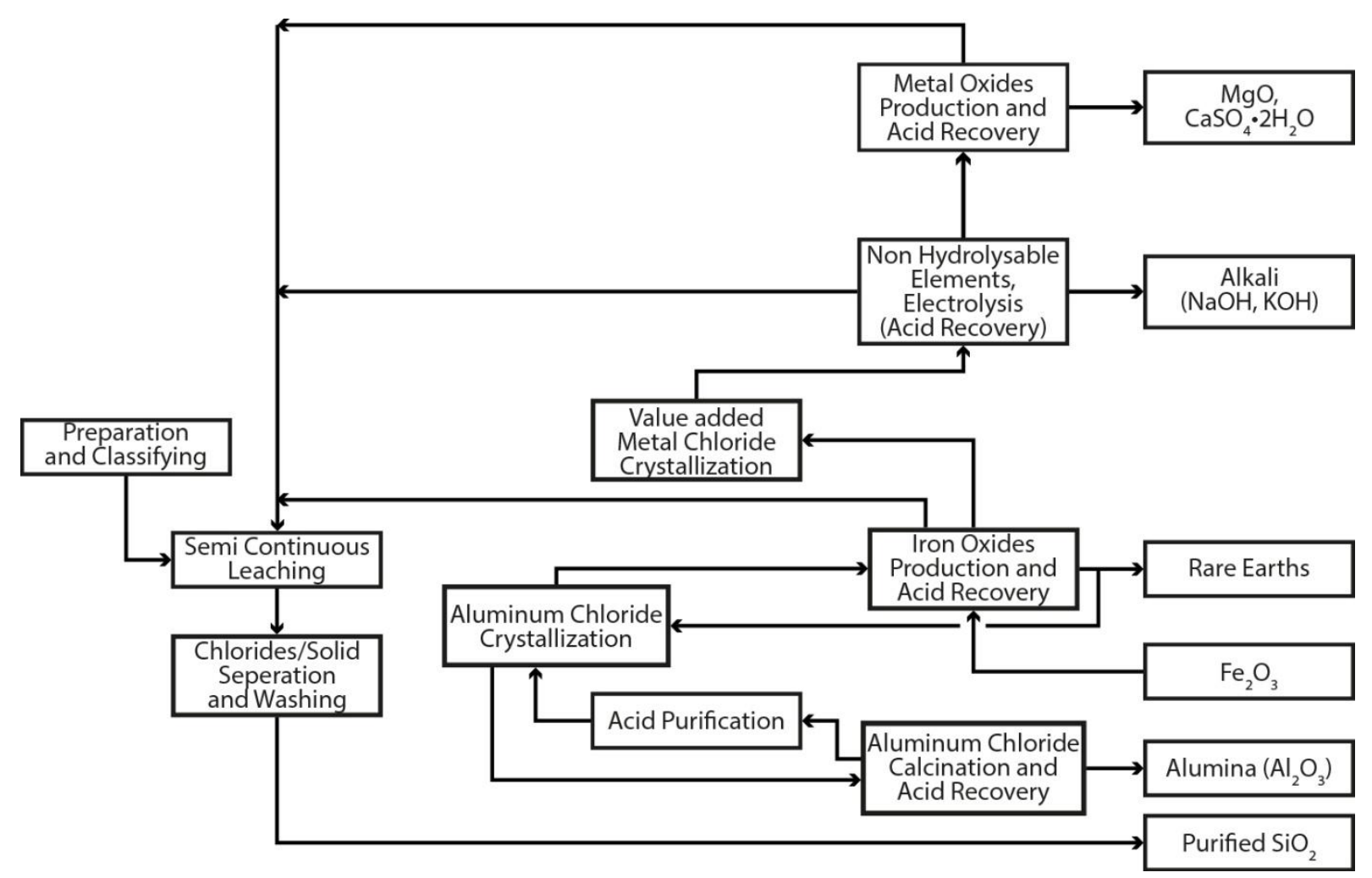

Figure 8. Flow sheet of the Canadian Orbite process for zero-waste valorisation of bauxite residue, including recovery of rare earths. Adapted from (Boudreault et al., 2013b).

Meanwhile, Russian researchers have reported that it is possible to efficiently leach scandium from bauxite residue in alkaline conditions (Yatsenko and Pyagai, 2010; Fomin et al., 2004). The development of the process was based on the observation that scandium forms a soluble anionic complex compound with carbonate ions (Pasechnik et al., 2004). Whereas only $0.43 \mathrm{~g} \mathrm{~L}^{-1} \mathrm{Sc}_{2} \mathrm{O}_{3}$ can be dissolved at $25{ }^{\circ} \mathrm{C}$ in a solution containing $100 \mathrm{~g} \mathrm{~L}^{-1} \mathrm{Na}_{2} \mathrm{CO}_{3}$, scandium is much better soluble in a $\mathrm{NaHCO}_{3}$ solution: $16.7 \mathrm{~g} \mathrm{~L}^{-1} \mathrm{Sc}_{2} \mathrm{O}_{3}$ can be dissolved in a solution containing $100 \mathrm{~g} \mathrm{~L}^{-1} \mathrm{NaHCO}_{3}$ (Fomin et al., 2004). In one version of the process, bauxite residue is leached with solutions of $\mathrm{Na}_{2} \mathrm{CO}_{3}$ and/or $\mathrm{NaHCO}_{3}(5-12 \%)$ in three steps at $50{ }^{\circ} \mathrm{C}$ for $2 \mathrm{~h}$ at a solid-to-liquid ratio of $1: 2.5$ to $1: 5$. The scandium is precipitated from the leachate by adding a solution of sodium aluminate or sodium zincate (prepared by dissolving 
$\mathrm{Al}_{2} \mathrm{O}_{3}$ or $\mathrm{ZnO}$ in an aqueous $\mathrm{NaOH}$ solution) while heating the solution for $2 \mathrm{~h}$ at $80{ }^{\circ} \mathrm{C}$. The resulting precipitate is separated from the solution, washed with an aqueous $\mathrm{NaOH}$ solution (10-25\%) with simultaneous heating until boiling, followed by filtration and washing with an aqueous $\mathrm{NaOH}$ solution (1-5\%). In a next step, the solid is dissolved in an aqueous $\mathrm{HCl}$ solution (1-5\%) and the remaining solid is filtered off. Scandium is precipitated as $\mathrm{Sc}(\mathrm{OH})_{3}$ by addition of an excess of an aqueous $\mathrm{NH}_{3}$ solution (10-25\%) to the filtrate (Diev et al., 2003). In a modified version of the process, leaching is carried out by passing a gas mixture containing air with $\mathrm{CO}_{2}\left(10-17\right.$ vol.\%) through the mixed $\mathrm{Na}_{2} \mathrm{CO}_{3} / \mathrm{NaHCO}_{3}$ solutions (Yatsenko et al., 2005). The leachate is first treated with an organic flocculant to precipitate titania, is subsequently electrolysed to remove impurities, and finally scandium is precipitated by sodium zincate in combination with an organic flocculant. In a further improved version of the process, multiple leaching steps with mixtures of sodium carbonate and sodium hydrogencarbonate are carried out while a flow of flue gases from the bauxite sintering or calcination furnaces (containing $\mathrm{CO}_{2}$ ) is passed through the solution (Yatsenko and Pyagai, 2010; Pyagai et al., 2012). Scandium is co-precipitated with zinc oxide. The advantage of alkaline leaching is that no acid is consumed to acidify the highly alkaline red mud sludge. The disadvantage is that only scandium can be recovered and not the other rare earths, because the other rare earths have a much weaker tendency to form soluble carbonato complexes .

The imidazolium ionic liquid 1-ethyl-3-methylimidazolium hydrogensulphate, $[\mathrm{EMIM}]\left[\mathrm{HSO}_{4}\right]$, has been used for high-temperature leaching of bauxite residue (Davris et al., 2014). At a temperature of $190{ }^{\circ} \mathrm{C}$, recovery was between 60 and $70 \%$ for most of the rareearth elements, although $100 \%$ recovery of lanthanum pas possible under some conditions. All of the iron and titanium present was solubilised, as well as about $35 \%$ of aluminium. Substitution of the ethyl group by a longer alkyl chain had little effect on the leaching 
efficiencies. By leaching with the carboxyl-functionalised ionic liquid betainium bis(trifluoromethylsulphonyl)imide, $[\mathrm{Hbet}]\left[\mathrm{Tf}_{2} \mathrm{~N}\right]$, a much higher selectivity for dissolution of the rare earths was achieved, even though the recovery percentages are lower than in $\left[\right.$ EMIM] $\left[\mathrm{HSO}_{4}\right]$. [Hbet] $\left[\mathrm{Tf}_{2} \mathrm{~N}\right]$ is able to selectively dissolve rare-earth oxides, leaving behind aluminium and iron oxides (Nockemann et al., 2006).

Bioleaching experiments on bauxite residue have been carried out with the acidproducing fungus Penicillium tricolor to remove the rare earths and radionuclides $(\mathrm{Qu}$ and Lian, 2013). The authors directly isolated from bauxite residue this strain of fungi, which can excrete the maximum amounts of organic acids (oxalic acid and citric acid). They tested the bioleaching efficiency under various bioleaching processes and pulp densities. The highest leaching efficiencies were found for yttrium and the heavy rare earths, followed by scandium. The lowest efficiencies were found for the light rare earths. This leaching behaviour is similar to what is observed for mineral acids.

Most combined pyro/hydrometallurgical treatments of bauxite residue use a pyrometallurgical step to first recover iron from bauxite residue and to subsequently concentrate the rare earths in an oxide slag (Liu et al., 2009b; Logomerac, 1979a; Logomerac, 1979b; Loginova et al., 2013). The efforts made to extract iron from bauxite residue have been described above. The hydrometallurgical step consists of leaching the rare earths from the slag with a diluted mineral acid (Sargic and Logomerac, 1974). During reductive smelting of bauxite residue, $98-99 \%$ of the scandium content reports to the slag phase (Tanutrov et al., 2013). Scandium has been recovered from slag obtained by smelting of Chinese bauxite residue, by leaching with $30 \% \mathrm{H}_{2} \mathrm{SO}_{4}$, followed by solvent extraction with bis(2ethylhexyl)phosphoric acid in sec-octanol/kerosene diluent, and stripping with NaF solution from the loaded organic phase to obtain $\mathrm{Na}_{3} \mathrm{ScF}_{6}(\mathrm{Xu}$ and $\mathrm{Li}, 1996)$ The combined use of pyrometallurgical and hydrometallurgical methods for recovery of metal values of bauxite 
residue is called complex processing (Zazubin et al., 1967; Sargic and Logomerac, 1974; Loginova et al., 2013).

\section{Mine tailings}

The older beneficiation methods to separate rare-earth ores from gangue were not very efficient. Large losses occurred during the flotation process of ground rare-earth ores, which has led to the cumulative generation of large volumes of solid waste still containing significant concentrations of rare earths (Jordens et al., 2013). This powdery solid waste was often dumped in tailing ponds close to the mine or the beneficiation plant. The concentrations in these residues are so high that these tailings can be considered as genuine rare-earth deposits. For instance, the tailings of the Mountain Pass mine in California are considered as the second largest rare-earth deposit in the United States (the largest being the Mountain Pass mine itself). The Mountain Pass mine tailings still contain between 3 to 5\% of rare-earth oxides. The recovery of rare earths from the huge polymetallic iron-niobium-REE deposit of Bayan Obo in Inner-Mongolia (China) is very inefficient. The deposit is mainly mined for its iron ore and only about $10 \%$ of the rare-earth content is recovered (Zhang et al., 2014). The situation is even worse for niobium, with virtually zero recovery of this metal. Concurrently, large volumes of mine tailings rich in rare earths are found near the Chinese rare-earth deposits or processing units (Xu and Peng, 2009). Also these "alternative" deposits represent a vast untapped resource of rare earths. The tailings in Baotou are receiving wide attention because they are polluting the environment with radioactive thorium-containing dust. More than 150 million of tonnes of tailings are being stored in a pond with an area of circa $12 \mathrm{~km}^{2}$ close to the Yellow River in Baotou city (Yu et al., 2012). Rare-earth-tailings from Bayan Obo ore in China have been used for the production of glass ceramics (Zhao et al., 2010; Luo 
and Xiao, 2011). Research is ongoing towards the concentration of the rare earths in the slag phase upon reductive smelting of the iron-rich Bayan Obo tailings. This work is discussed in section 6 on metallurgical slags. Carbochlorination is a promising method for the recovery of rare earths, thorium and niobium from the tailings of Bayan Obo ore (Yu et al., 2012). The tailings powders are mixed and heated in a stream of chlorine gas at 550 to $600{ }^{\circ} \mathrm{C}$, transforming the metal compounds into chlorides. Some of these metal chlorides are volatile and can be removed from the reaction mixture by sublimation. Chloride salts of the rare earths and thorium are left behind in the solid residue, and can be subsequently recovered. Another approach to solubilise the rare earths and niobium from the Bayan Obo tailings is by sulphating roasting at $250{ }^{\circ} \mathrm{C}$, followed by leaching with water at $60{ }^{\circ} \mathrm{C}$ (Zhang et al., 2014). Not only during the beneficiation process, but also during the cracking of rare-earth ores by acids or bases, significant amounts of rare earths are lost. Likewise, the historical processing of monazite has generated large volumes of rare-earth-rich tailings at Rhodia Solvay's rareearth processing plant at La Rochelle (France).

More efficient extraction of rare earths from old mine tailings would not only give an easy access to significant amounts of rare earths, but is also beneficial from an environmental point of view as this could be integrated in remediating mine sites through either in situ landfill mining or ex situ landfill mining (Jones et al., 2013; Jones et al., 2012). In the former case the metals are extracted in situ; in the latter case the residues are excavated and further processed to recover any critical metals and to, ideally, valorise the remaining mineral phases in other applications, in line with the zero-waste principle (see further).

Economically interesting concentrations of rare earths are found not only near rare-earth mines, but at tailing deposits of other mines as well. For instance, apatite associated with iron ores often contains significant amounts of rare-earth elements. The apatite-rich rocks on the tailings of the iron mines of the Mineville district, New York (USA), are a typical example 
(Long et al., 2010). Reddish-brown apatite of this deposit contains between 5.8 and $20.6 \mathrm{wt} \%$ total rare earths, the green variety between 0.5 and $2.0 \mathrm{wt} \%$, and the white and transparent varieties only trace amounts. Monazite and bastnäsite fill microfractures in apatite crystals. The tailings of the Pea Ridge iron ore mine, Washington County, Missouri (USA) contain considerable amounts of rare earths (Grauch et al., 2010; Long et al., 2010). The rare earths are present in the material from breccia pipes that cross-cut the magnetite-hematite ore body and its altered rhyolite host rock. The main rare-earth-bearing ore minerals are monazite and xenotime, that are present as fine grains within apatite. The apatite does not occur only in the breccia, but is also dispersed throughout the whole iron ore body. The apatite itself contains minor amounts of rare earths in its crystal structure. Besides the rare earths, the breccia contains significant concentrations of gold, silver and tin. The Pea Ridge deposit is a highgrade rare-earth deposit (on average $12 \mathrm{wt} \%$ rare-earth oxides, estimated total: 72,000 metric tonnes) and is relatively rich in heavy rare earths and yttrium. In Europa, apatite-iron ores are found in the Kiruna area in northern Sweden (Palsson et al., 2014). The main rare-earth minerals are apatite, monazite and allanite. Flotation tests have been carried out on the solid materials from the tailing pond in order to concentrate the rare-earth-containing minerals. Haine and Filippov explored the potential to recover rare earths from the waste generated by kaolin (China clay) extraction plants in Cornwall, UK (Dehaine and Filippov, 2014). The kaolin deposits are formed by weathering of granite rocks. In the micaceous waste fraction, the rare earths are concentrated in monazite grains, and the main rare earths are cerium, lanthanum and neodymium. Likewise, tailings of uranium mines often contain large concentrations of rare earths. For instance, tailings of uranium mines in Queensland (Australia), Kazachstan and Kyrgyzstan are presently under investigation as possible new rare-earth "alternative deposits" (Golev et al., 2014). Furthermore, tailings of titanium mines could also offer possibilities for the extraction of rare earths (Jha et al., 2008). Ilmenite is 
transformed into water-insoluble alkali titanate and water-soluble ferrite by alkali roasting (Sanchez-Segado et al., 2015; Jha et al., 2011; Lahiri and Jha, 2009). After roasting, the insoluble alkali titanate is separated from the rare-earth oxide mixture in colloidal form and water-soluble ferrite. Further leaching of alkali titanate is carried out with oxalic acid and ascorbic acid solutions, to remove the remaining $\mathrm{Fe}^{2+}$ ions into the leachate and to precipitate a high-purity synthetic rutile containing more than $95 \% \mathrm{TiO}_{2}$. The mining tailings of tin placer deposits often contain considerable amounts of monazite and xenotime (Szamalek et al., 2013). Cassiterite is the main tin ore in these deposits.

On the other hand, an interesting source of scandium can be found in the residues of the processing of tungsten ores (Xu and Li, 1996; Natansohn et al., 1992; Gokhale and Bhat, 1967; Guo et al., 1988). If pressurised leaching with aqueous alkali is used to yield sodium wolframate from wolframite, scandium is left behind in the tungsten residue. Scandium can be recovered from this residue by leaching with $\mathrm{HCl}$ solution, followed by solvent extraction with bis(2-ethylhexyl)phosphoric acid (D2EPHA). Scandium can also be recovered from the residues generated during the processing of tin, nickel, tantalum and niobium ores (Wang et al., 2011b).

\section{Coal ash and incinerator ash}

Coal contains trace concentrations of many elements, including rare earths. These elements, with the exception of volatile elements such as mercury and cadmium, end up in the bottom and fly ashes of power plants after burning the coal for electricity production (Querol et al., 1995). The burning of coal leads to an enrichment of some metals in the ashes so that these ashes be considered as low-grade ores for different metals (Seredin and Finkelman, 2008; Seredin et al., 2013; Franus et al., 2015). Concentrations of more than $0.1 \%$ of rare- 
earth oxides are often found in coal ashes (Seredin and Dai, 2012). Ashes from coal of the Russian Far East contain even more than 1\% of rare-earth oxides (Seredin, 1996). Given the fact that still huge amounts of coal are burnt worldwide - despite the negative environmental and climate impact of this energy source - coal ashes could be an important source of rare earths (Calus-Moszko and Bialecka, 2013). It has been recommended to use method similar to those used for the extraction of rare earths from weathered crust deposits (ion adsorption clays) (Blissett et al., 2014). Experiments to leach rare earths with dilute $\mathrm{H}_{2} \mathrm{SO}_{4}$ from coal fly ash have been carried out (Kashiwakura et al., 2014). First, a fast dissolution of the rare earths on the surface of the ash particles was observed, followed by slow dissolution of the rare earths inside the particles. In a patented process, it has been proposed to leach the rare earths from coal ashes by dilute $\mathrm{HNO}_{3}$, followed by solvent extraction with TBP (Joshi et al., 2013). In another process, it is proposed to leach the rare earths with $\mathrm{HCl}$ from coal fly ash (Boudreault et al., 2013a).

Ashes from oil shales are another potential resource of rare earths (Yang et al., 2010). Extraction of rare earths from these ashes is a challenge due to the high iron and aluminium contents relative to the rare-earth concentrations. A conceptual flow sheet for the recovery of rare earths was proposed, consisting of four steps: (1) leaching with $\mathrm{HCl}$; (2) removal of iron by solvent extraction with the trialkylamine N235; (3) selective precipitation of aluminium and rare earths as hydroxide and separation from impurities; (4) dissolution of the hydroxides in $\mathrm{HNO}_{3}$, followed by extraction of the rare earths by TBP to remove them from other metals dissolved in the solution.

The ashes of incineration plants contain a wide variety of metals. A study of the ashes of a Swiss incineration plant burning municipal solid waste showed that the concentrations of rare earths are very low and the extraction of these elements from the ashes would not be economically feasible (Morf et al., 2013). Analysis of the metal content of a Danish 
incineration plant gave similar low concentrations of rare earths (Allegrini et al., 2014). The concentration of rare earths in Chinese medical waste incinerator ashes was found to be lower than the crustal abundance of the rare earths (Zhao et al., 2008). Research on the ashes of incineration plants show that landfills storing municipal waste are unlikely to become a resource of rare earths, although these landfills often contain high concentrations of base metals (Jones et al., 2013; Jones et al., 2012). This is not a surprise, given the fact that widespread use of rare-earth products (e.g. neodymium permanent magnets) in consumer goods is only a quite recent phenomenon. The situation could be different in the case of some specialised industrial landfills, for instance landfills storing lamp phosphor waste from Endof-Life fluorescent lamps.

\section{Metallurgical slags}

Efficient pyrometallurgical processes have been developed for the recovery of metal values from electronic scrap, spent automobile exhaust catalysts and spent industrial catalysts. In its Hoboken site near Antwerp (Belgium) Umicore operates an integrated smelter and refining plant for recovering metals from Waste Electrical and Electronic Equipment (WEEE) (Felix and Vanriet, 1994; Meskers et al., 2009; Vanbellen and Chintinne, 2006). Recovered metals include: silver, gold, indium, bismuth, tin, selenium, tellurium, antimony, arsenic, the platinum-group metals (platinum, palladium, ruthenium, rhodium, iridium) and the base metals copper, nickel and lead. However, the employed metallurgical flow sheets have not been developed for the recovery of rare earths. Due to the high affinity of the rare-earth metals for oxygen, these elements end up in diluted (oxidic) form in the slag of the so-called "copper smelter" and finally in the slag of the lead blast furnace. Moreover, the rare-earth content of these slags consists largely of cerium, which is not a critical metal. In fact, there is 
an oversupply of cerium, due to the large natural abundance of cerium and its relatively low demand (Binnemans et al., 2013b). Other companies such as Aurubis and Boliden use pyrometallurgical processes comparable to that of Umicore for the multi-metal recycling from electronic scrap, but none of cases the rare earths are recovered from the slag phases (Boliden, 2014; Aurubis, 2014).

Concurrently, pyrometallurgical flow sheets for the recycling of valuable metals from batteries can produce a slag relatively rich in rare earths. In 2011, Rhodia (Solvay) and Umicore announced that they had jointly developed a process for recycling of rare earths from nickel metal hydride rechargeable batteries (Anonymous, 2011; Rhodia, 2011). Although the details of the process have not been disclosed, it is based on Umicore's patented Ultra High Temperature (UHT) smelting technology (Cheret and Santen, 2007). An industrial-scale pilot plant is operational in Hoboken since September 2011 and this pilot plant has an initial annual capacity of 7000 tonnes, corresponding to approximately 150000 (hybrid) electric vehicle batteries or 250 million mobile phone batteries (Umicore, 2011; Umicore, 2009). Not only nickel metal hydride batteries, but also lithium-ion batteries could be recycled in this facility. At this moment, the process has been optimised for End-of-Life portable nickel metal hydride batteries. The batteries are fed in a vertical shaft furnace, together with a small amount of coke and a slag former (Cheret and Santen, 2007). At the bottom of the shaft furnace, oxygenenriched air is injected into the furnace. The process requires relatively little external energy input, because the combustion of both the plastic casing of the batteries and the organic electrolytes releases large amounts of energy. The metals are converted into a $\mathrm{Ni}-\mathrm{Co}-\mathrm{Cu}-\mathrm{Fe}$ alloy and a slag. The slag consists mainly of oxides of calcium, aluminium, silicon, and iron, and also contains lithium and rare earths (Verhaeghe et al., 2011). These oxide slags can be processed to recover lithium and to produce rare-earth concentrates that are subsequently used 
as a feed in the rare-earth separation plant of Solvay (formerly Rhodia) in La Rochelle, France.

In comparison to natural ores, slags have the advantage that the formation of mineral phases during cooling can be influenced by use of different slag formers, cooling rates and furnace conditions. This processing of slags is defined as hot stage slag engineering (Durinck et al., 2008). The slag composition and microstructure can be changed by adjusting the primary pyrometallurgical process directly or immediately after separation of the slag from the molten metal, while the slag is still at high temperature. If a metal can be enriched in a certain mineralogical slag phase embedded in a matrix of other minerals by choosing a suitable slag composition and cooling trajectory, then a separation of this mineral phase might be possible by conventional ore processing methods. The metal could be much more effectively extracted from the resulting mineral concentrate than by processing the complete slag (Elwert et al., 2014). To present, interest from academia for research on the recovery of rare earths from metallurgical slags has been limited. Müller and Friedrich investigated the recycling of nickel metal hydride batteries and measured the rare-earth content in $\mathrm{CaO}-\mathrm{SiO}_{2}-$ $\mathrm{CaF}_{2}$ based slag both in laboratory tests and pilot scale trials (Muller and Friedrich, 2006; Muller and Friedrich, 2004). As expected, the rare-earth metals collected in the slag phase and a rare-earth-rich slag (50-60 wt\% rare earths) were obtained. In a pyrometallurgical process for recycling of NiMH batteries, the batteries were first dismantled (Tang et al., 2013). In a next step, the electrodes and the polymer were heated to $600{ }^{\circ} \mathrm{C}$ to combust the organic components. After separation of nickel metal from the black powder that contained $\mathrm{NiO}, \mathrm{CoO}$ and the rare earths, the powder was further treated by a slagging process using a calcium silicate slag. Nickel and cobalt were recovered as an iron-copper-cobalt-nickel alloy and the rare earths reported to the slag phase. The affinity of neodymium and dysprosium to phosphate-containing phases was investigated for the $\mathrm{Al}_{2} \mathrm{O}_{3}-\mathrm{CaO}-\mathrm{MgO}-\mathrm{P}_{2} \mathrm{O}_{5}-\mathrm{SiO}_{2}$ slag 
system, with slags originating from pyrometallurgical recycling of NdFeB magnets (Elwert et al., 2014). In the phosphate-free $\mathrm{Al}_{2} \mathrm{O}_{3}-\mathrm{CaO}-\mathrm{MgO}-\mathrm{SiO}_{2}$ slag system, dysprosium and neodymium were more or less randomly distributed throughout the different silicate phases, although local enrichments of up to $15 \mathrm{wt} \%$ of rare-earth oxides were found. Addition of $\mathrm{P}_{2} \mathrm{O}_{5}$ led to the formation of a britholite-like silicophosphate, with up to $57 \mathrm{wt} \%$ of rare-earth oxides. This phase formed at an early stage of the cooling process and it is assumed that it scavenged the rare earths before the silicate phases were crystallising. Even at a content of $\mathrm{P}_{2} \mathrm{O}_{5}$ as low as $4.57 \%$, the concentration of rare-earth oxides in the silicate matrix phase was already very strongly reduced. This shows that the rare earths in slags have a strong affinity for phosphate-containing phases. A rare-earth-rich slag has been obtained by a pyrometallurgical process based on carbon-bearing pellet reduction and melting technology to recover iron from complex ores of Bayan Obo in China (Ding et al., 2012; Ding et al., 2013). The main mineral phases of the ore were iron oxides, bastnäsite-(Ce) and fluorite. During the smelting process, nearly all the rare earths reported to the slag phase and the resulting slag contained $14 \%$ of rare-earth oxides. The slag was remelted at $1400{ }^{\circ} \mathrm{C}$ and the melt was cooled using three types of cooling conditions (water quenching, air cooling, and furnace cooling) to investigate the influence of cooling on the microstructure and phase characteristics of the slag. The rare-earth elements were concentrated in a cerium calcium silicate phase and could be leached from the slag by $4 \mathrm{M} \mathrm{HCl}$, leaving behind $\mathrm{CaF}_{2}$ and $\mathrm{ThO}_{2}$. The recovery of the rare earths was more than $97 \%$ in all cases; the lowest recovery was observed for the water-quenched slag, while the highest recoveries (> 99\%) were observed for the air-cooled and the furnace-cooled slag. The recovery of the rare earths from the original slag was in between the two extremes. One could wonder whether remelting of the slag is justified from an economic point of view, since it resulted in only $1 \%$ extra leaching of the rare earths. Although the rare earths report to a cerium calcium silicate slag phase, europium and 
scandium do not. These rare earths are concentrated in rare-earth-containing barium fluorophlogopite phase (Zheng and Lin, 1994). This rare-earth-rich phase could be collected from crushed and powdered slag by a flotation process. Another type of rare-earth-rich slag was obtained by the reductive smelting of a magnetite ore containing monazite (Kim et al., 2014). The authors investigated the kinetics of lanthanum leaching from this slag by $0.3 \mathrm{M}$ $\mathrm{H}_{2} \mathrm{SO}_{4}$. Scandium reports to the slag phase during the reduction of tungsten residue in an electric arc furnace (Xu and $\mathrm{Li}, 1996)$.

Additionally, some information on the presence of rare-earth oxides in flux powders used in the continuous casting of steels is available, as well as on slag resulting from the smelting of rare-earth-containing iron ores (Zheng and Lin, 1994; Anacleto et al., 1993; Derevyankin et al., 1981a; Derevyankin et al., 1981b; Fang et al., 2001; Jia et al., 1995; Lin and Zheng, 1997; Yang et al., 2011). A wealth of information on the formation of rare-earth-containing minerals in magmas is available in the geological community, although geological conditions and time scales may not be very relevant for rare-earth-recovery operations. The available thermodynamic data for rare earths elements in FactSage, the most widely used thermodynamic calculation system for high temperature oxide systems, is fairly limited (Factsage, 2013). In order to make the recovery of rare earths from metallurgical slags more efficient, the problem of dilution of the rare earths in oxide slags has to be solved. Once the rare earths have been concentrated into solid rare-earth-rich phases, they can subsequently be removed much more easily from these phases by acid leaching.

\section{Waste water}

Waste water could also be a source for rare earths, but the potential of this waste stream for the recovery of rare earths is largely unexplored. In the first instance, rare earths could be 
recovered from waste water produced during the extraction and separation of rare earths. Acid mine drainage (AMD) often contains considerable concentrations of rare earths (Merten and Buchel, 2004; Protano and Riccobono, 2002; Delgado et al., 2012). AMD is the outflow of acidic water from (old) metal mines or coal mines, and it is often heavily contaminated by metals (Akcil and Koldas, 2006). Some studies report on the possibility to recover uranium and other metals from AMD by ion-exchange resins or by biosorption, but limited information is available on the possibility to recover rare earths (Roig et al., 1997; Geremias et al., 2003; Fu and Wang, 2011). Whereas solvent extraction is the preferred method for recovery of rare-earth ions from concentrated aqueous waste streams and pregnant leach solutions, this method is not recommended for removal of rare-earth ions from diluted aqueous waste streams, because of the unavoidable contamination of the aqueous phase by organic solvents. Therefore, ion-exchange resins and chelating resins are to be preferred. Yantasee and co-workers have investigated the possibility to bind rare-earth ions by functional groups on the surface of a mesoporous silica support (Yantasee et al., 2009). It has been proposed to use these materials for recovery of rare earths from acidic industrial waste water streams and mining effluents. Nanoporous silica surface modified with 3,4hydroxypyridinone was tested for the recovery of cerium and europium from aqueous solutions (Johnson et al., 2012). The mechanism of the uptake of rare earths by chitosan functionalised with EDTA or DTPA has been studied (Roosen and Binnemans, 2014; Inoue, 2000; Roosen et al., 2014). Functionalised magnetic nanoparticles are efficient for the capture of rare-earth elements from water, and such nanoparticles can be easily retrieved from the solution by a permanent magnet (Dupont et al., 2014a; Dupont et al., 2014b; Legaria et al., 2015). Also functionalized non-magnetic nanoparticles such as $\mathrm{SiO}_{2}$ have been used for uptake of rare-earth ions from aqueous solutions, but recovery of the metals is less straightforward than with magnetic nanoparticles (Dupont et al., 2014a; Topel et al., 2014). 
Although the biosorption of precious metals and uranium by algae, fungi, bacteria and yeast has been widely explored, up to now relatively little attention has been paid to the biosorption of rare earths (Das and Das, 2013; Philip et al., 2000; Anagnostopoulos and Symeopoulos, 2008; Tsuruta, 2007; Moriwaki and Yamamoto, 2013; Andres et al., 2003). The fungus Ganoderma lucidum has been tested for the uptake of rare earths and thorium from waste water from the processing of monazite (Muraleedharan et al., 1994). By-pass cement dust (BCD) has been tested as a cheap adsorbent for rare-earth ions from aqueous solutions (Ali et al., 2011). BCD is a by-product of the manufacture of Portland cement and is generated during the calcination process in the kiln. This fine-grained material mainly consists of calcium oxide. Supported flowerlike nano- $\mathrm{Mg}(\mathrm{OH})_{2}$ exhibits a large specific surface area and high extraction ability for rare earths (Li et al., 2013). Pilot-scale experiments showed that this material is promising to recycle rare earths from industrial waste water.

\section{Towards zero-waste valorisation}

\subsection{Concept of zero-waste valorisation}

In this paper we have used the term "valorisation" to refer to the economically viable utilisation of a material stream which was hitherto considered as a non-valuable waste stream. The term "valorisation" differs from the official meaning of the word in UK English where it is described as the increase in the value of capital assets through the application of valueforming labour in production. However, as the term "valorisation" has been used for many years by a multitude researchers in the context of "slag valorisation" (Jones et al., 2009) or "waste valorisation", we also employ it in this meaning in the present review paper. Hence, valorisation of industrial process residues implies that a certain value is created in a costeffective way. 
When considering the valorisation of rare-earth containing secondary resources, one can take a straightforward metal-centric approach in which the most valuable rare-earths are extracted from the residue. As these metals form only a minor fraction of the overall residue the chosen metal-centric processing method is only delivering a suboptimal solution, in which the largest fraction of the residue is not catered for, often implying that more costly and environmentally-unfavourable stockpiling or landfilling is required. It is clear that this metalcentric approach is not in line with the whole-system approach that is conveyed by the zerowaste philosophy. The latter strives to eliminate waste at source and at all points down the supply chain, thereby rejecting one-way linear resource-use in favour of a "closed-loop" circular system (Curran and Williams, 2012). In the zero-waste vision, "waste" is considered as the symbol of an inefficient society where resources are badly allocated (Zaman and Lehmann, 2013; Zaman, 2014). Zero-waste, therefore, envisions that all industrial inputs are somehow being used in final products or converted into value-added feedstocks for other industries or processes. This vision is completely in-line with the industrial symbiosis approach, in which distinct industries are re-organised into clusters in such a way that each company's by-products match the input requirements of another industry, whereby the integrated whole produces (near) zero wastes (Curran and Williams, 2012). As pointed out by ZWIA, products and processes need to be designed and managed to avoid and eliminate waste and to recover all resources from a given waste stream (ZWIA, 2004). For industry greater competitiveness can be obtained, representing a continuation of the inevitable drive towards (resource) efficiency (Curran and Williams, 2012). Translated to the domain of zero-waste valorisation of metal-containing industrial process residues, this implies that a rare-earth metal-centric recovery approach needs to be replaced by a product-centric, whole system approach, in which (almost) all components of the residue need to be turned into value, i.e. "valorised". The rejection of a metal-centric in favour of a product-centric approach has 
received ample attention in the most recent UNEP report Metal Recycling - Opportunities, Limits, Infrastructure (Reuter et al., 2013). Although the concept was mainly developed for the integrated valorisation of critical and technology metal containing End-of-Life products (cf. Waste Electrical and Electronic Waste, WEEE), it is perfectly fit for secondary resources as well. In the context of End-of-Life products, it has been pointed out that the product-centric view considers the complex metallurgy of all elements at the same time, optimising both the metallurgy and recycling infrastructure in order to minimise losses, but also addressing the related issues, such as liberation, sorting and consumer recycling (Reuter and van Schaik, 2013). The work of Reuter and colleagues demonstrates that zero-waste valorisation will require more than the development of technological solutions, as also pointed out by Klauber et al. (Klauber et al., 2011). In the case of industrial process residues, the "secondary resource" should thus be regarded as a polymetallic raw material product, also hosting a number of potentially valuable minerals. Zero-waste, product-centric valorisation, therefore, means that tailored, integrated flow sheets need to be designed to recover both critical and base metals, while simultaneously finding solutions for the residual mineral matrix as well. For instance, in the case of stocks of previously produced bauxite residue, this zero-waste vision implies that all valuable metals (including the lanthanides and scandium) etc. need to be recovered, while valorising the mineral matrices into, for example, innovative construction materials. In the case of future bauxite residues or phosphogypsum, an even more ideal, whole-system scenario is to redesign the overall flow sheet upstream so that different residues are generated, which can find better valorisation options further downstream the valorisation chain. The zero-waste valorisation concept is now discussed in more detail for phosphogypsum (section 8.2) and bauxite residue (section 8.3). 


\subsection{Towards zero-waste valorisation of phosphogypsum}

Phosphogypsum could be used as a resource for the manufacturing of cement, plasters and gypsum construction materials, but the high contents of fluorides, phosphates and watersoluble sodium compounds turn phosphogypsum into a raw material that is of an inferior quality compared to natural gypsum or anhydrite for these applications. Also organic matter can cause problems. After or during the recovery of the metal values, phosphogypsum needs to be treated before it can be used in the construction industry. Lokshin and co-workers described a zero-waste valorisation approach for the processing of phosphogypsum, which includes purification of phosphogypsum on dumps by percolation leaching with dilute $\mathrm{H}_{2} \mathrm{SO}_{4}$ solutions to remove these fluorides, phosphates and water-soluble sodium compounds of sodium, with simultaneous dissolution of rare-earth sulphates (Lokshin et al., 2013). Indian phosphogypsum was purified by treating it with a 10-20\% aqueous ammonia solution, followed by washing with water (Singh et al., 1993). The purified phosphogypsum was tested on a lab scale for cement manufacturing and the produced Portland cement was found to have properties similar to cement produced from the mineral gypsum.

Another approach is to purify phosphogypsum by treating it with a $3-4 \mathrm{wt} \%$ citric acid solution, followed by washing with water (Singh, 2002). This treatment transforms phosphate and fluoride impurities in water-soluble citrates, aluminates and iron compounds. The residue can be used for the production of Portland cement or gypsum plaster. The Belgian company Prayon SA has recently developed an integrated process to recover rare earths from phosphogypsum by leaching with $\mathrm{H}_{2} \mathrm{SO}_{4}$, yielding a pure, white residue that can be valorised as a construction material (Germeau et al., 2013).

One particular point of attention for the zero-waste valorisation of phosphogypsum is the fact that phosphate rocks are slightly radioactive due to the presence of uranium and its decay 
products. The contribution of thorium to the radioactivity of phosphate rock is low, due to the very low thorium concentrations in phosphate rock. Upon the acid attack of phosphate rock, the radioactive equilibrium existing in the phosphate rock is disturbed and a redistribution of the radionuclides occurs. Most of the uranium and thorium report to the phosphoric acid and subsequently finish up in the phosphate fertiliser, while radium will be incorporated in the phosphogypsum since it shows chemical similarities to calcium (Papastefanou et al., 2006; Hull and Burnett, 1996). Also polonium will end up in the phosphogypsum. Four radionuclides in phosphogypsum are of concern: ${ }^{226} \mathrm{Ra},{ }^{231} \mathrm{~Pa},{ }^{210} \mathrm{~Pb}$ and ${ }^{210} \mathrm{Po}$ (Vanderheijde et al., 1990). Most attention has been paid to the radium content of phosphogypsum. Phosphogypsum may contain specific activities of ${ }^{226} \mathrm{Ra}$ between one and two orders of magnitude higher than those of natural gypsum, depending on the uranium content of the ore (Menzel, 1968). Due to the enrichment of radionuclides, phosphogypsum is classified as a technologically enhanced naturally occurring radioactive material (TENORM) (Shakhashiro et al., 2010; Tayibi et al., 2009; Gezer et al., 2012). The decay of ${ }^{226} \mathrm{Ra}$ in the phosphogypsum will result in the formation and reappearance of daughter nuclides and radioactive equilibrium will be re-established. Radiological measurements on phosphogypsum of Thessaloniki (Greece) showed that the activity of ${ }^{226} \mathrm{Ra}$ varied between 261 to $688 \mathrm{~Bq} \mathrm{~kg}^{-1}$, with a mean value of $508 \mathrm{~Bq} \mathrm{~kg}^{-1}$ (Papastefanou et al., 2006). It must be mentioned that also part of the uranium originally present in the phosphate rock ends up in the phosphogypsum (with the concentration depending on the type of phosphate rock and the chemical process used), so that also daughter elements of ${ }^{238} \mathrm{U}$ can be found in the phosphogypsum (Rutherford et al., 1994). The possible inhalation of the radon $\left({ }^{222} \mathrm{Rn}\right)$ formed by the decay of ${ }^{226} \mathrm{Ra}$ is considered as a health concern (Haridasan et al., 2002). Several authors have investigated the activities of radionuclides in phosphogypsum at different geographic locations. Hence, more information is available on radioactivity issues of phosphogypsum compared to bauxite residue (red mud) 
(see section 4) (Rutherford et al., 1994; Mazzilli et al., 2000; Saueia et al., 2005; Azouazi et al., 2001; Hull and Burnett, 1996; Zielinski et al., 2011; Papastefanou et al., 2006; Paridaens and Vanmarcke, 2008; Paridaens and Vanmarcke, 2001; Vanderheijde et al., 1990). The presence of radionuclides in phosphogypsum is of concern when phosphogypsum is valorised, both at the stage of rare earths recovery and during the transformation of phosphogypsum into cement, plaster or other building materials. This implies that safety measures are required when working with phosphogypsum in order to avoid uncontrolled release of the radionuclides and to avoid the risk of exposure of the workers to those radionuclides. In the conversion of phosphogypsum to ammonium sulphate by reaction with ammonium carbonate, all the radionuclides that were originally present in the phosphogypsum $\left({ }^{226} \mathrm{Ra},{ }^{210} \mathrm{~Pb}\right.$ and ${ }^{210} \mathrm{Po}$ ) will report to the calcium carbonate by-product (Burnett et al., 1996). As a result, the ammonium sulphate fertiliser will have a very low radioactivity. However, it must be taken into account that the concentration of radionuclides in the calcium carbonate has consequences if this calcium carbonate is further treated for recovery of rare earths.

Recovery of rare earths from phosphogypsum could be combined with removal of radionuclides, as part of remediation or recultivation of old phosphogypsum stacks to leave the landfills in a safer condition. If the phosphogypsum is not of a high enough quality for use in plaster or similar applications, excavation and ex situ leaching of the radionuclides and rare earths is not a feasible option. In such cases, in situ leaching could be option. This approach implies injecting lixiviants in the phosphogypsum stack, followed by collection of the leachates and recovery of the dissolved metals. No studies on in situ leaching of phosphogypsum stacks have been done yet, although in situ leaching is commonly used for recovery of metals from low grades ores, especially from low grade uranium ores (Gupta and Singh, 2003). However, in situ leaching can only be applied if precautions are taken to avoid contamination of ground water. 


\subsection{Towards zero-waste valorisation of bauxite residue}

Zero-waste valorisation of bauxite residue implies not only removal of the rare earths and other metal values, but also finding applications for the metal-lean residues. Unlike some other high volume industrial wastes such as fly ash and metallurgical slag, bauxite residue currently finds no major industrial applications, besides minor use in cement and ceramic production (Pontikes and Angelopoulos, 2013; Liu and Zhang, 2011). Many researchers have already looked at the valorisation of bauxite residue, apart from its valorisation in the construction industry (Paramguru et al., 2005; Sushil and Batra, 2008; Liu et al., 2009b; Bhatnagar et al., 2011; Klauber et al., 2011; Liu and Wu, 2012). The removal of rare earths can be done in a preprocessing step consisting of leaching the rare earths from bauxite residue, followed by further processing of the remaining residue for recovery of the other metal metals (Piga et al., 1993). However, other processing schemes are possible. For instance, the rare earths could be removed from the slag that are formed during the removal of iron as pig iron.

Bauxite residue has a high (base) metal content and extraction of metals from bauxite residue might be economically feasible. Iron oxide is a main constituent of bauxite residue (up to $60 \%$ of the mass) and causes its red colour. In view of the rather large content of iron oxide, attempts have been made in the past to use bauxite residue as a source of iron. Iron recovery studies were initiated as early as in the 1950s and may be classified into two major approaches, i.e. smelting and solid state reduction (Hammond et al., 2013). In the former, bauxite residue is treated in a blast furnace in the presence of a reducing agent where the iron oxides are reduced, generating pig iron and a titanium-rich slag (also containing the rare earths) (Ercag and Apak, 1997; Kumar et al., 2006; Xenidis et al., 2011; Logomerac, 1979a; 
Raspopov et al., 2013). In the solid-state reduction, bauxite residue is mixed with a reducing agent or contacted with a reducing gas at certain temperature, resulting in the formation of metallic iron or the conversion of ferric iron to magnetite, which can be used in a next step as feed for a conventional blast furnace (Xenidis et al., 2009; Samouhos et al., 2013; Chun et al., 2014; Liu et al., 2009a). So far, these iron recovery processes have not been commercially successful. The large sodium content of bauxite residue prohibits the use of blast furnaces. The high temperatures lead to the evaporation of sodium oxide in the lower (hotter) regions of the blast furnace and its re-deposition in the colder regions, where it attacks the ceramic refractory bricks and also leads to the formation of so-called sodium nests. These sodium nests are hard outgrowths that obstruct the free flow of the charge inside the furnace. Moreover, bauxite residue contains a lot of water, which would have to be removed first, thus representing a high cost if fossil fuels are used for drying. The solid-state reduction process, resulting into a beneficiated stream of magnetite, appears feasible but most likely economically not viable.

A concurrent valorisation of the iron and iron-lean residue, designed for bauxite residue, would possibly address the above. This implies a mentality shift from the concept of introducing bauxite residue into an existing process, to the concept where a process is developed specifically for bauxite residue. Obviously, the commitment of resources in the second trajectory is much higher, although it could be the way forward. An example of that approach is the ENEXAL bauxite residue treatment process (Balomenos et al., 2014; Balomenos et al., 2013). Through electric arc furnace carbothermic smelting, bauxite residue is fully converted into two marketable products: pig iron and mineral wool. Pig iron is used in the secondary steel industry as a steel scrap substitute, while the mineral wool can applied for the production of thermo-acoustic insulating products for the construction industry. No solid or liquid waste products are generated in this process, and thus in conjunction with the 
alumina refinery plant, zero-waste valorisation of the bauxite ore can be achieved. This novel process has been applied for more than a year in Aluminium of Greece's industrial scale pilot plant. So recovery of rare earths is not done in the ENEXAL process, but new process flow sheets with recovery of rare earths could be developed.

Besides iron, bauxite residue also contains economically relevant concentrations of aluminium and titanium. High silica contents in bauxites result in reduced $\mathrm{Al}_{2} \mathrm{O}_{3}$ recovery in the Bayer process since a part of the dissolved $\mathrm{Al}_{2} \mathrm{O}_{3}$ will precipitate in the form of complex aluminosilicates, e.g. cancrinite $\mathrm{Na}_{6} \mathrm{Ca}_{2}\left[\mathrm{Al}_{6} \mathrm{Si}_{6} \mathrm{O}_{24}\right]\left(\mathrm{CO}_{3}\right)_{2}$ (Smith, 2009). Re-feeding these residues in the Bayer process does not result in recovering significant amounts of alumina. In conjunction with losses during the digestion and settling in the Bayer process, bauxite residue contains as a result up to $20 \mathrm{wt} \% \mathrm{Al}_{2} \mathrm{O}_{3}$ which is a serious loss for the industry. To achieve $\mathrm{Al}_{2} \mathrm{O}_{3}$ recovery from high-silica bauxite residues, several processes have been developed in the past. The "MgO- $\mathrm{Na}_{2} \mathrm{CO}_{3}$ sinter process" involves adding $\mathrm{MgO}$ to bauxite residue and sintering at $900-1100{ }^{\circ} \mathrm{C}$ (Meher et al., 2011a). A variant of this method is the " $\mathrm{BaO}-\mathrm{Na}_{2} \mathrm{CO}_{3}$ sinter process", which also achieves high alumina recovery as dissolved sodium aluminates and low silicon dissolution (Meher et al., 2011b). An alternative to the sintering process is the Orbite process which uses high temperature $\mathrm{HCl}$ leaching to dissolve aluminium and iron as chlorides (Boudreault et al., 2013b). Efforts have also been made to recover titanium from bauxite residue by leaching with $\mathrm{H}_{2} \mathrm{SO}_{4}$ (Gatzini-Leonardou et al., 2008; Sayan and Bayramoglu, 2004). The recovery of metal values from bauxite residue has been reviewed recently (Liu and Naidu, 2014).

In fact, the work on alumina extraction should be seen in a wider scope and be coupled also with the iron removal as a first step. In this approach, a great amount of work already done in the early 1960s by the US Bureau of Mines on clays, could be now extrapolated both on bauxite residue and iron-lean slags (e.g. from the ENEXAL process) (Balomenos et al., 
2014; Balomenos et al., 2013). The processes investigated on clays were based on $\mathrm{HNO}_{3}$, sulphurous acid, $\mathrm{HCl}$-isopropyl ether extraction, lime-soda with wet or dry grind option, $\mathrm{H}_{2} \mathrm{SO}_{4}$-electrolytic iron removal, $\mathrm{H}_{2} \mathrm{SO}_{4}$-chemical iron removal and potassium alum (Peters et al., 1967). The most promising acid processes were those based on $\mathrm{HCl}$ and $\mathrm{HNO}_{3}$, with the separation of dissolved iron and aluminium salts, recovery of acid and crystallisation of an aluminium salt of sufficient purity to yield reduction-grade alumina identified as the major challenges to overcome (Goldberg, 1970).

Considering that bauxite residue contains small quantities of radionuclides (mainly ${ }^{232} \mathrm{Th}$, ${ }^{238} \mathrm{U},{ }^{226} \mathrm{Ra}$ ), bauxite residue can be classified as Technologically Enhanced Naturally Occurring Radioactive Material (TENORM) and falls under the legislation for NaturallyOccurring Radioactive Materials (NORM) (Klauber et al., 2011; O'Connor et al., 2013; Qin and $\mathrm{Wu}, 2011$; Gu et al., 2012; Somlai et al., 2008). These legal constraints have to be taken into account when bauxite residues are used in building materials. One could think of developing a process to leach out the radionuclides together with the rare earths, so the resulting bauxite residue would have very low radiation levels. However, this implies that downstream processing of the rare-earth-containing leachates should also include a step to safely dispose of the radionuclides present in these solutions.

\section{Conclusions and outlook}

In general, the concentrations of rare earths in industrial waste streams are low, typically less than $1 \%$ of rare-earth oxides. However, since the available waste volumes are huge, the total amount of rare earths in these waste fractions is very substantial, so that they can represent an interesting alternative source of rare earths, complementing rare earths obtained through primary mining and recycling of End-of-Life product flows. The recovery of rare 
earths and other valuable elements can be part of a remediation process of historic landfills of industrial wastes. Recovery of valuable metals from industrial waste streams must be integrated in larger recycling schemes that recover most (base) metals and also find applications for the residues left after removal of the metals. The recovery of metals must thus be part of zero-waste valorisation schemes of industrial waste streams. Whereas radioactivity is not an issue in case of recycling of rare earths from End-of-Life consumer goods, it can be a serious issue in the case of processing industrial waste streams such as bauxite residue (red mud) or phosphogypsum. From an economic point of view, the most interesting industrial waste stream is bauxite residue because of its high concentrations of scandium. Extraction of scandium from bauxite residue can be an economically feasible industrial process, especially if bauxite residues with high scandium content can be processed, for instance Greek or Jamaican bauxite residues. Phosphogypsum can be a potential resource of light rare earths, but it is recommended to integrate the production of phosphoric acid and the recovery of the rare earths into one process, so that the rare earths are not incorporated in the phosphogypsum. It is a challenge to develop economically feasible and environmentallyfriendly "new metallurgical systems" for the recovery of rare earths from industrial waste streams containing low concentrations of rare earths. However, as (heavy) rare earth prices tend to increase, recovery flow sheets for industrial process residues will become more attractive. By also finding medium to high value outlets for the other residues arising during these flow sheets, the overall business case of such flow sheets can be further improved. To provide more resilience to the rare-earth and raw materials industry, innovative fundamental and applied research in this field should, therefore, be of strategic interest, targeting comprehensive "new metallurgical systems". These research activities can provide medium to long term answers for a likely situation in the future when the demand for (heavy) rare earths exceeds the available supply. Concerted efforts will be required as much of the reported 
research data have been obtained on a trial-and-error basis, rather than on the basis of a rational design. Presently, only limited information is available with respect to the mineralogy of the different rare-earth rich phases in bauxite residue, phosphogypsum and metallurgical slag. Knowledge of these phases could aid the development of new more efficient leaching processes. There is also a need for methods that allow efficient recovery of rare-earth ions from dilute aqueous solutions, not only from waste water streams, but especially from the dilute leachates. Due to the fact that the concentrations of rare earths in industrial waste residues are low compared to primary rare-earth ores and reclaimed End-of-Life consumer goods (WEEE), tailored, zero-waste processes dedicated to the recovery of rare earths from these dilute waste streams must be developed.

\section{Acknowledgments}

The authors thank the KU Leuven for financial support (GOA/13/008, DBOF and IOF-KP RARE $^{3}$ ). YP acknowledges the Research Foundation - Flanders (FWO-Flanders) for a postdoctoral fellowship. 


\section{References}

Abhilash, Sinha, S., Sinha, M.K., Pandey, B.D., 2014. Extraction of lanthanum and cerium from Indian red mud. Int. J. Miner. Process. 127, 70-73.

Akcil, A. and Koldas, S., 2006. Acid Mine Drainage (AMD): causes, treatment and case studies. J. Clean. Prod. 14, 1139-1145.

Ali, O.I.M., Osman, H.H., Sayed, S.A., Shalabi, M.E.H., 2011. The removal of some rare earth elements from their aqueous solutions on by-pass cement dust (BCD). J. Hazard. Mater. $195,62-67$.

Allegrini, E., Maresca, A., Olsson, M.E., Holtze, M.S., Boldrin, A., Astrup, T.F., 2014. Quantification of the resource recovery potential of municipal solid waste incineration bottom ashes. Waste Manage. 34, 1627-1636.

Anacleto, N.M., Lee, H.G., Hayes, P.C., 1993. Sulfur Partition Between CaO-SiO $2-\mathrm{Ce}_{2} \mathrm{O}_{3}$ Slags and Carbon-Saturated Iron. ISIJ Int. 33, 549-555.

Anagnostopoulos, V. and Symeopoulos, B., 2008. A preliminary study of europium uptake by yeast cells. The case of Kluveromyces Marxianus. Nuclear Proficiency Testing 1036, 203209.

Anderson, C.D., Anderson, C.G., Taylor, P.R., 2013. Survey of recycled rare earths metallurgical processing. Can. Metall. Q. 52, 249-256.

Andres, Y., Texier, A.C., Le Cloirec, P., 2003. Rare earth elements removal by microbial biosorption: A review. Environ. Technol. 24, 1367-1375. 
Anonymous, 1966. Phosphate rock may be new rare-earth source. Chem. Eng. News 44, 5253.

Anonymous, 2011. Rhodia, Umicore to Recycle Rare Earths. Chem. Eng. News 89, 16.

Aurubis, 2014. Metal Recycling.

Azouazi, M., Ouahidi, Y., Fakhi, S., Andres, Y., Abbe, J.C., Benmansour, M., 2001. Natural radioactivity in phosphates, phosphogypsum and natural waters in Morocco. J. Environ. Radioactiv. 54, 231-242.

Badwal, S.P.S., Ciacchi, F.T., Milosevic, D., 2000. Scandia-zirconia electrolytes for intermediate temperature solid oxide fuel cell operation. Solid State Ionics 136, 91-99.

Balomenos, E., Gianopoulou, I., Panias, D., Paspaliaris, I., 2013. EAF Treatment for the Efficient and Complete Exploitation of the Bauxite Residue (Red Mud) Produced in the Bayer Process. Proceedings of the European Metallurgical Conference EMC 2013 285-292.

Balomenos, E., Kastritis, D., Panias, D., Paspaliaris, I., Boufounos, D., 2014. The ENEXAL bauxite residue treatment process: Industrial scale pilot plant results. Light Metals 2014 (ed J. Grandfield), John Wiley \& Sons, Inc. , Hoboken, NJ, USA. doi: 10.1002/9781118888438.ch25, 143-146.

Becker, P., 1989. Phosphates and phosphoric acid: raw materials, technology, and economics of the wet process, 2nd edition, Fertilizer Science and Technology Series Volume: 6. Marcel Dekker, New York.

Benmore, R.A., Coleman, M.L., Mcarthur, J.M., 1983. Origin of Sedimentary Francolite from Its Sulfur and Carbon Isotope Composition. Nature 302, 516-518. 
Bhatnagar, A., Vilar, V.J.P., Botelho, C.M.S., Boaventura, R.A.R., 2011. A review of the use of red mud as adsorbent for the removal of toxic pollutants from water and wastewater. Environ. Technol. 32, 231-249.

Binnemans, K. and Jones, P.T., 2014. Perspectives for the recovery of rare earths from endof-life fluorescent lamps. J. Rare Earths 32, 195-200.

Binnemans, K., Jones, P.T., Blanpain, B., Van Gerven, T., Yang, Y.X., Walton, A., Buchert, M., 2013a. Recycling of rare earths: a critical review. J. Clean. Prod. 51, 1-22.

Binnemans, K., Jones, P.T., Van Acker, K., Blanpain, B., Mishra, B., Apelian, D., 2013b. Rare-Earth Economics: The Balance Problem. JOM 65, 846-848.

Binnemans, K., Pontikes, Y., Jones, P.T., Van Gerven, T., Blanpain, B., 2013c. Recovery of rare earths from industrial waste residues: a concise review. Proceedings of the Third International Slag Valorisation Symposium (19-20 March 2013, Leuven, Belgium) 191-205.

Blissett, R.S., Smalley, N., Rowson, N.A., 2014. An investigation into six coal fly ashes from the United Kingdom and Poland to evaluate rare earth element content. Fuel 119, 236-239.

Boliden, 2014. Smelters.

Borra, C.R., Pontikes, Y., Binnemans, K., Van Gerven, T., 2015. Leaching of rare earths from bauxite residue (red mud). Miner. Eng. in press, doi:10.1016/j.mineng.2015.01.005.

Boudreault, R., Fournier, J., Primeau, D., 2013a. Processes for treating fly ashes. Patent WO 2013142957

Boudreault, R., Fournier, J., Primeau, D., Labrecque-Gilbert, M.M., 2013b. Processes for treating red mud. Patent WO 2013104059 A1 
Bray, E.L., 2014. Mineral Commodity Summaries: Bauxite and Alumina 2014. U.S.

Geological Survey,

Bunus, F. and Dumitrescu, R., 1992. Simultaneous Extraction of Rare-Earth Elements and Uranium from Phosphoric-Acid. Hydrometallurgy 28, 331-338.

Bunus, F., Miu, I., Dumitrescu, R., 1994. Simultaneous Recovery and Separation of Uranium and Rare-Earths from Phosphoric-Acid in A One-Cycle Extraction Stripping Process. Hydrometallurgy 35, 375-389.

Bunus, F.T., 2000. Uranium and rare earth recovery from phosphate fertilizer industry by solvent extraction. Miner. Process. Extr. Metall. Rev. 21, 381-478.

Burnett, W.C., Schultz, M.K., Hull, C.D., 1996. Radionuclide flow during the conversion of phosphogypsum to ammonium sulfate. J. Environ. Radioactiv. 32, 33-51.

Calus-Moszko, J. and Bialecka, B., 2013. Analysis of the Possibilities of Rare Earth Elements Obtaining from Coal and Fly Ash. Gospod. Surowcami Min. 29, 67-80.

Cheret, D., Santen, S., 2007. Battery Recycling. US Patent 7,169,206

Chun, T.J., Zhu, D.Q., Pan, J., He, Z., 2014. Preparation of metallic iron powder from red mud by sodium salt roasting and magnetic separation. Can. Metall. Q. 53, 183-189.

Curran, T. and Williams, I.D., 2012. A zero waste vision for industrial networks in Europe. J. Hazard. Mater. 207, 3-7.

Das, N. and Das, D., 2013. Recovery of rare earth metals through biosorption: An overview. J. Rare Earths 31, 933-943. 
Davris, P., Balomenos, E., Panias, D., Paspaliaris, I., 2014. Leaching of rare earths from bauxite residues using imidazolium based ionic liquids. Proceedings of the 1st European Rare Earth Resources Conference (ERES 2014), Milos (Greece), 4-7 September 2014 241-252.

Dehaine, Q. and Filippov, L.O., 2014. Rare earth (La, Ce, Nd) and rare metals (Sn, Nb, W) as by-product of kaolin production, Cornwall: Part1: Selection and characterisation of the valuable stream. Miner. Eng. doi:10.1016/j.mineng.2014.10.006.

Delgado, J., Perez-Lopez, R., Galvan, L., Nieto, J.M., Boski, T., 2012. Enrichment of rare earth elements as environmental tracers of contamination by acid mine drainage in salt marshes: A new perspective. Mar. Pollut. Bull 64, 1799-1808.

Derevyankin, V.A., Gasik, M.I., Anelok, L.I., Porotnikova, T.P., Vukelich, S.B., 1981a. Study of lanthanum- and scandium-containing phases of aluminum-calcium slags. Izv. Vyssh. Uchebn. Zaved., Tsvetn. Metall. 84-85.

Derevyankin, V.A., Porotnikova, T.P., Kocherova, E.K., Yumasheva, I.V., 1981b. Behavior of scandium and lanthanum during red mud treatment. Izv. Vyssh. Uchebn. Zaved., Tsvetn. Metall. 119-120.

Derevyankin, V.A., Porotnikova, T.P., Kocherova, E.K., Yumasheva, I.V., Moiseev, V.E., 1981c. Behavior of scandium and lanthanum in the production of alumina from bauxite. Izv. Vyssh. Uchebn. Zaved., Tsvetn. Metall. 86-89.

Diev, V.N., Sabirzyanov, N.A., Skryabneva, L.M., Yatsenko, S.P., Anashkin, V.S., Aminov, S.N., Zavadskii, K.F., Sysoev, A.V., Ustich, E.P., 2003. Recovery of scandium from wastes in processing of bauxite ores for alumina manufacture. Russian Patent RU2201988 
Ding, Y.G., Wang, J.S., Wang, G., Xue, Q.G., 2012. Innovative Methodology for Separating of Rare Earth and Iron from Bayan Obo Complex Iron Ore. ISIJ Int. 52, 1772-1777.

Ding, Y.G., Xue, Q.G., Wang, G., Wang, J.S., 2013. Recovery Behavior of Rare Earth from Bayan Obo Complex Iron Ore. Metall. Mater. Trans. B 44, 28-36.

Dupont, D., Brullot, W., Bloemen, M., Verbiest, T., Binnemans, K., 2014a. Selective Uptake of Rare Earths from Aqueous Solutions by EDTA-Functionalized Magnetic and Nonmagnetic Nanoparticles. ACS Appl. Mater. Interfaces 6, 4980-4988.

Dupont, D., Luyten, J., Bloemen, M., Verbiest, T., Binnemans, K., 2014b. Acid-Stable Magnetic Core-Shell Nanoparticles for the Separation of Rare Earths. Ind. Eng. Chem. Res. $53,15222-15229$.

Durinck, D., Engstrom, F., Arnout, S., Heulens, J., Jones, P.T., Bjorkman, B., Blanpain, B., Wollants, P., 2008. Hot stage processing of metallurgical slags. Resour. Conserv. Recy. 52, 1121-1131.

EI-Didamony, H., Gado, H.S., Awwad, N.S., Fawzy, M.M., Attallah, M.F., 2013. Treatment of phosphogypsum waste produced from phosphate ore processing. J. Hazard. Mater. 244, 596-602.

El-Didamony, H., Ali, M.M., Awwad, N.S., Fawzy, M.M., Attallah, M.F., 2012. Treatment of phosphogypsum waste using suitable organic extractants. J. Radioanal. Nucl. Chem. 291, 907914.

Elwert, T., Goldmann, D., Schirmer, T., Strauss, K., 2014. Affinity of Rare Earth Elements to Silico-Phosphate Phases in the System $\mathrm{Al}_{2} \mathrm{O}_{3}-\mathrm{CaO}-\mathrm{MgO}-\mathrm{P}_{2} \mathrm{O}_{5}-\mathrm{SiO}_{2}$. Chem. Ing. Tech. 86, 840-847. 
Ercag, E. and Apak, R., 1997. Furnace smelting and extractive metallurgy of red mud:

Recovery of $\mathrm{TiO}_{2}, \mathrm{Al}_{2} \mathrm{O}_{3}$ and pig iron. J. Chem. Technol. Biot. 70, 241-246.

Factsage, 2013.

Fang, X., Hu, L., Tan, R., Wang, Z., 2001. Recycling of rare earth ferrosilicon smelting slag. Chinese Patent CN1302910A

Felix, N., Vanriet, C., 1994. Recycling of Electronic Scrap at UMS Hoboken Smelter.

Precious Metals 1994, Proceedings of the 18th International Precious Metals Conference, Vancouver, Canada, June 1994, pp. 159-169.

Fomin, E.S., Sabirzyanov, N.A., Anashkin, V.S., Yatsenko, S.P., Diev, V.N., 2004. New approaches to processing of the muds of alumina production. Travaux ICSOBA 31, 66-71.

Franus, W., Wiatros-Motyka, M.M., Wdowin, M., 2015. Coal fly ash as a resource for rare earth elements. Environ. Sci. Pollut. Res. DOI 10.1007/s11356-015-4111-9.

Fu, F.L. and Wang, Q., 2011. Removal of heavy metal ions from wastewaters: A review. J. Environ. Manage. 92, 407-418.

Fulford, G.D., Lever, G., Sato, T., 1991a. Recovery of rare earth elements from red mud. US Patent 5,030,424

Fulford, G.D., Lever, G., Sato, T., 1991b. Recovery of rare earth elements from sulphurous acid solution by solvent extraction. US Patent 5,015,447

Galvanek, P., 1959. Process of recovering uranium from its ores. US Patent 2,875,023

Gambogi, J., 2014. Mineral Commodity Summaries: Rare Earths 2014. U.S. Geological Survey, 
Gatzini-Leonardou, S., Oustadakis, P., Tsakiridis, P.E., Markopoulos, C., 2008. Titanium leaching from red mud by diluted sulfuric acid at atmospheric pressure. J. Hazard. Mater. 157, $579-586$.

Gelencser, A., Kovats, N., Turoczi, B., Rostasi, A., Hoffer, A., Imre, K., Nyiro-Kosa, I., Csakberenyi-Malasics, D., Toth, A., Czitrovszky, A., Nagy, A., Nagy, S., Acs, A., Kovacs, A., Ferincz, A., Hartyani, Z., Posfai, M., 2011. The Red Mud Accident in Ajka (Hungary): Characterization and Potential Health Effects of Fugitive Dust. Environ. Sci. Technol. 45, $1608-1615$.

Geremias, R., Pedrosa, R.C., Benassi, J.C., Favere, V.T., Stolberg, J., Menezes, C.T.B., Laranjeira, M.C.M., 2003. Remediation of coal mining wastewaters using chitosan microspheres. Environ. Technol. 24, 1509-1515.

Germeau, A., Guidi, T., Fati, D., 2013. Method for treating phosphate rock. Patent WO 2013060689 A1

Gezer, F., Turhan, S., Ugur, F.A., Goren, E., Kurt, M.Z., Ufuktepe, Y., 2012. Natural radionuclide content of disposed phosphogypsum as TENORM produced from phosphorus fertilizer industry in Turkey. Ann. Nucl. Energy 50, 33-37.

Gokhale, Y.W. and Bhat, T.R., 1967. Determination of Scandium in Wolframite and in Residues Obtained After Extraction of Tungsten. Talanta 14, 435-437.

Goldberg, D.C., 1970. Processes for extracting alumina from nonbauxite ores, report of the National Research Council (U.S.), National Materials Advisory Board, Panel on Potentials of Aluminum Extractive Processes. Publication NMAB-278. 
Golev, A., Scott, M., Erskine, P.D., Ali, S.H., Ballantyne, G.R., 2014. Rare earths supply chains: Current status, constraints and opportunities. Res. Policy 41, 52-59.

Grafe, M. and Klauber, C., 2011. Bauxite residue issues: IV. Old obstacles and new pathways for in situ residue bioremediation. Hydrometallurgy 108, 46-59.

Grafe, M., Power, G., Klauber, C., 2011. Bauxite residue issues: III. Alkalinity and associated chemistry. Hydrometallurgy 108, 60-79.

Grauch, R.I., Verplanck, P.L., Seeger, C.M., Budahn, J.R., Van Gosen, B.S., 2010. Chemistry of Selected Core Samples, Concentrate, Tailings, and Tailings Pond Waters: Pea Ridge Iron (Lanthanide-Gold) Deposit, Washington County, Missouri. Open-File Report 2010-1080 U.S. Department of the Interior, U.S. Geological Survey, Reston, Virginia

Grinstead, R.R., 1958. Process for utilizing organic orthophosphate extractants. US Patent $2,860,031$

Grinstead, R.R., 1959a. Process for the recovery of metals from high-lime carnotite ores. US Patent $2,869,980$

Grinstead, R.R., 1959b. Slurry solvent extraction process for the recovery of metals from solid materials. US Patent 2,869,979

Gu, H.N., Wang, N., Liu, S.R., 2012. Radiological restrictions of using red mud as building material additive. Waste Managem. Res. 30, 961-965.

Guo, G.Y., Chen, Y.L., Li, Y., 1988. Solvent-Extraction of Scandium from Wolframite Residue. J. Met. 40, 28-31. 
Gupta, C.K. and Krishnamurthy, N., 1992. Extractive Metallurgy of Rare-Earths. Int. Mater. Rev. 37, 197-248.

Gupta, C.K. and Krishnamurthy, N., 2004. Extractive Metallurgy of Rare Earths. CRC Press.

Gupta, C.K. and Singh, H., 2003. Uranium Resource Processing - Secondary Resources. Spinger, Berlin.

Habashi, F., 1985. The Recovery of the Lanthanides from Phosphate Rock. J. Chem. Technol. Biot. A 35, 5-14.

Habashi, F., 1989. Insitu and Dump Leaching Technology - Application to Phosphate Rock. Fert. Res. 18, 275-279.

Habashi, F., 1994. Phosphate fertiliser industry processing technology. Industrial Minerals $318,65-69$.

Habashi, F., 1998. Solvent extraction in the phosphate fertilizer industry. Epd Congress 1998 201-218.

Habashi, F., 2013. Extractive metallurgy of rare earths. Can. Metall. Q. 52, 224-233.

Habashi, F. and Awadalla, F.T., 1986. The Recovery of Uranium and Lanthanides During the Production of Nitrophosphate Fertilizers Using Tertiary Amyl Alcohol. J. Chem. Technol. Biot. 36, 1-6.

Habashi, F. and Awadalla, F.T., 1988. Insitu and Dump Leaching of Phosphate Rock. Ind. Eng. Chem. Res. 27, 2165-2169.

Habashi, F., Awadalla, F.T., Yao, X.B., 1987. The Hydrochloric-Acid Route for Phosphate Rock. J. Chem. Technol. Biot. 38, 115-126. 
Habashi, F., Awadalla, F.T., Zailaf, M., 1986. The Recovery of Uranium and the Lanthanides from Phosphate Rock. J. Chem. Technol. Biot. 36, 259-266.

Hammond, K., Mishra, B., Apelian, D., Blanpain, B., 2013. CR ${ }^{3}$ Communication: Red Mud A Resource or a Waste? JOM 65, 340-341.

Haridasan, P.P., Maniyan, C.G., Pillai, P.M.B., Khan, A.H., 2002. Dissolution characteristics of Ra-226 from phosphogypsum. J. Environ. Radioactiv. 62, 287-294.

Hull, C.D. and Burnett, W.C., 1996. Radiochemistry of Florida phosphogypsum. J. Environ. Radioactiv. 32, 213-238.

Innocenzi, V., De Michelis, I., Kopacek, B., Veglio, F., 2014. Yttrium recovery from primary and secondary sources: A review of main hydrometallurgical processes. Waste Manage. 34, 1237-1250.

Inoue, K., 2000. Chromatographic separation of rare earths with complexane types of chemically modified chitosan. in: Peter, M.G., Domard, A., and Muzzarelli, R.A.A. (Eds.), Advances in Chitin Science Vol 4. (Proceedings of the 3rd International Conference of the European Chitin Society) Universität Potsdam, Potsdam, pp. 460-465.

International Aluminium Institute, 2013. Bauxite Residue Management: Best Practice.

Jarosinski, A., Kowalczyk, J., Mazanek, C., 1993. Development of the Polish Wasteless Technology of Apatite Phosphogypsum Utilization with Recovery of Rare-Earths. J. Alloys Compd. 200, 147-150.

Jasinski, S.M., 2014. Mineral Commodity Summaries: Phosphate 2014. U.S. Geological Survey, 
Jha, A., Lahiri, A., Kumari, E.J., 2008. Beneficiation of titaniferous ores by selective separation of iron oxide, impurities and rare earth oxides for the production of high grade synthetic rutile. Trans. Inst. Min. Metall., Sect. C 117, 157-165.

Jha, A., Cooke, G., Lahiri, A., Kumari, E.J., 2011. The Alkali Roasting and Leaching of Ilmenite Minerals For the Extraction of High Purity Synthetic Rutile and Rare-earth Oxides. Energy Technology 2011: Carbon Dioxide and Other Greenhouse Gas Reduction Metallurgy and Waste Heat Recovery 183-195.

Jia, Y.L., Dong, Y.C., Qin, Z.Z., 1995. Experimental Research of Physical-Properties of the Re-Refining Slag. J. Rare Earths 13, 133-136.

Johansson, N., Krook, J., Eklund, M., Berglund, B., 2013. An integrated review of concepts and initiatives for mining the technosphere: towards a new taxonomy. J. Clean. Prod. 55, 3544.

Johnson, B.E., Santschi, P.H., Chuang, C.Y., Otosaka, S., Addleman, R.S., Douglas, M., Rutledge, R.D., Chouyyok, W., Davidson, J.D., Fryxell, G.E., Schwantes, J.M., 2012. Collection of Lanthanides and Actinides from Natural Waters with Conventional and Nanoporous Sorbents. Environ. Sci. Technol. 46, 11251-11258.

Jones, B.E.H. and Haynes, R.J., 2011. Bauxite Processing Residue: A Critical Review of Its Formation, Properties, Storage, and Revegetation. Crit. Rev. Env. Sci. Tec. 41, 271-315.

Jones, P.T., Geysen, D., Guo, M.Q., and Blanpain, B., 2009. Proceedings of the First Slag Valorisation Symposium, 6-7 April 2009, Leuven, Belgium. ACCO, Leuven.

Jones, P.T., Geysen, D., Tielemans, Y., Pontikes, Y., Blanpain, B., Mishra, B., Apelian, D., 2012. Closing Material Loops: The Enhanced Landfill Mining Concept. JOM 64, 743-744. 
Jones, P.T., Geysen, D., Tielemans, Y., Van Passel, S., Pontikes, Y., Blanpain, B., Quaghebeur, M., Hoekstra, N., 2013. Enhanced Landfill Mining in view of multiple resource recovery: a critical review. J. Clean. Prod. 55, 45-55.

Jones, P.T., Van Gerven, T., Van Acker, K., Geysen, D., Binnemans, K., Fransaer, J., Blanpain, B., Mishra, B., Apelian, D., 2011. CR ${ }^{3}$ : Cornerstone to the sustainable inorganic materials management $\left(\mathrm{SIM}^{2}\right)$ research program at KU Leuven. JOM 63, 14-15.

Jordens, A., Cheng, Y.P., Waters, K.E., 2013. A review of the beneficiation of rare earth element bearing minerals. Miner. Eng. 41, 97-114.

Joshi, P.B., Preda, D.V., Skyler, D.A., Tsinberg, A., Green, B.D., Marinelli, W.J., 2013. Recovery of Rare Earth Elements and Compounds from Coal Ash. US Patent 20130287653 Kashiwakura, S., Kumagai, Y., Kubo, H., Wagatsuma, K., 2014. Dissolution of Rare Earth Elements from Coal Fly Ash Particles in a Dilute $\mathrm{H}_{2} \mathrm{SO}_{4}$ Solvent. Open J. Phys. Chem. 3, 6975.

Kim, C.J., Yoon, H.S., Chung, K.W., Lee, J.Y., Kim, S.D., Shin, S.M., Lee, S.J., Joe, A.R., Lee, S.I., Yoo, S.J., Kim, S.H., 2014. Leaching kinetics of lanthanum in sulfuric acid from rare earth element (REE) slag. Hydrometallurgy 146, 133-137.

Klauber, C., Grafe, M., Power, G., 2011. Bauxite residue issues: II. options for residue utilization. Hydrometallurgy 108, 11-32.

Kobayashi, S., 1999. Scandium triflate in organic synthesis. Eur. J. Org. Chem. 15-27.

Koopman, C., Hoogerwerf, M., Witkamp, G.J., 1999a. In-line removal of impurities by ion exchange during a recrystallization step in the phosphoric acid production process. Rewas'99 
Global Symposium on Recycling, Waste Treatment and Clean Technology Volume I-Iii $1745-1753$.

Koopman, C., Witkamp, C.J., Van Rosmalen, G.M., 1999b. Removal of heavy metals and lanthanides from industrial phosphoric acid process liquors. Sep. Sci. Technol. 34, 2997-3008.

Koopman, C. and Witkamp, G.J., 2000. Extraction of lanthanides from the phosphoric acid production process to gain a purified gypsum and a valuable lanthanide by-product. Hydrometallurgy 58, 51-60.

Kruse, J.M., 1963. Process for the selective recovery of uranium directly from uraniumbearing ores. US Patent 3,089,885

Kumar, B.N., Radhika, S., Kantam, M.L., Reddy, B.R., 2011. Solid-liquid extraction of terbium from phosphoric acid solutions using solvent-impregnated resin containing TOPS 99. J. Chem. Technol. Biot. 86, 562-569.

Kumar, B.N., Radhika, S., Reddy, B.R., 2010. Solid-liquid extraction of heavy rare-earths from phosphoric acid solutions using Tulsion CH-96 and T-PAR resins. Chem. Eng. J. 160, 138-144.

Kumar, S., Kumar, R., Bandopadhyay, A., 2006. Innovative methodologies for the utilisation of wastes from metallurgical and allied industries. Resour. Conserv. Recy. 48, 301-314.

Kuwabara, H., Atsukawa, M., Nishimoto, Y., Iwaiya, Y., 1967. Process of recovering valuable components from red mud. US Patent 3,311,449

Lahiri, A. and Jha, A., 2009. Novel Alkali Roasting of titaniferous minerals and leaching for the production of synthetic rutile. Energy Technology Perspectives: Conservation, Carbon Dioxide Reduction and Production from Alternative Sources 115-125. 
Legaria, E.P., Topel, S.D., Kessler, V.G., Seisenbaeva, G.A., 2015. Molecular insights into the selective action of a magnetically removable complexone-grafted adsorbent. Dalton Trans. 44, 1273-1282.

Leveque, A., Sabot, J.L., 1981. Procédé de recupération globale de l'uranium, des terres rares, du thorium et de l'yttrium appliqué au traitement de phosphogypse. French patent FR2485506-A2

Li, C.R., Zhuang, Z.Y., Huang, F., Wu, Z.C., Hong, Y.P., Lin, Z., 2013. Recycling Rare Earth Elements from Industrial Wastewater with Flowerlike Nano- $\mathrm{Mg}(\mathrm{OH})_{2}$. ACS Appl. Mater. Interfaces 5, 9719-9725.

Lin, H.K. and Zheng, X.P., 1997. Process mineralogy of scandium and europium-containing iron-making slag. Miner. Metall. Proc. 14, 18-20.

Liu, D.Y. and Wu, C.S., 2012. Stockpiling and Comprehensive Utilization of Red Mud Research Progress. Materials 5, 1232-1246.

Liu, W.C., Yang, J.K., Xiao, B., 2009a. Application of Bayer red mud for iron recovery and building material production from alumosilicate residues. J. Hazard. Mater. 161, 474-478.

Liu, W.C., Yang, J.K., Xiao, B., 2009b. Review on treatment and utilization of bauxite residues in China. Int. J. Miner. Process. 93, 220-231.

Liu, X.M. and Zhang, N., 2011. Utilization of red mud in cement production: a review. Waste Managem. Res. 29, 1053-1063.

Liu, Y.J. and Naidu, R., 2014. Hidden values in bauxite residue (red mud): Recovery of metals. Waste Manage. 34, 2662-2673. 
Loginova, I.V., Kyrchikov, A.V., Lebedev, V.A., Ordon, S.F., 2013. Investigation into the question of complex processing of bauxites of the srednetimanskoe deposit. Russ. J. NonFerr. Met. 54, 143-147.

Logomerac, V.G., 1971. Distribution of rare-earth and minor elements in some bauxite and red mud produced. Proceedings of the 2nd International Symposium of the ICSOBA (6-10 October 1969, Budapest, Hungary) 383-393.

Logomerac, V.G., 1979a. Complex utilization of red mud by smelting and solvent extraction. Trav. Com. Int. Etude Bauxites, Alumine Alum. 15, 279-285.

Logomerac, V.G., 1979b. The complex utilization of red mud or low grade bauxite by solvent extraction. Special Volume - Canadian Institute of Mining and Metallurgy, Proc. Int. Solvent Extr. Conf. , 1977 21, 516-520.

Lokshin, E.P. and Tareeva, O.A., 2010. Recovery of lanthanides from extraction phosphoric acid produced by the dihydrate process. Russ. J. Appl. Chem. 83, 951-957.

Lokshin, E.P., Tareeva, O.A., Elizarova, I.P., 2011. Processing of Phosphodihydrate to Separate Rare-Earth Elements and Obtain Gypsum Free from Phosphates and Fluorides. Russ. J. Appl. Chem. 84, 1461-1469.

Lokshin, E.P., Tareeva, O.A., Elizarova, I.R., 2013. On integrated processing of phosphogypsum. Russ. J. Appl. Chem. 86, 463-468.

Lokshin, E.P., Vershkova, Y.A., Vershkov, A.V., Tareeva, O.A., 2002. Leaching of lanthanides from phosphohemihydrate with nitric acid. Russ. J. Appl. Chem. 75, 1753-1759.

Long, K.R., Van Gosen, B.S., Foley, N.K., Cordier, D., 2010. The principal rare earth elements deposits of the United States - A summary of domestic deposits and a global 
perspective. Scientific Investigations Report 2010-5220 U.S. Department of the Interior, U.S. Geological Survey, Reston, Virginia

Luo, W.Y. and Xiao, Z.H., 2011. Preparation of glass-ceramic materials from rare earth tailings. Adv. Mat. Res. 236-238, 460-463.

Mazzilli, B., Palmiro, V., Saueia, C., Nisti, M.B., 2000. Radiochemical characterization of Brazilian phosphogypsum. J. Environ. Radioactiv. 49, 113-122.

Meher, S.N., Rout, A.K., Padhi, B.K., 2011a. Extraction of Alumina from Red Mud by Divalent Alkaline Earth Metal Soda Ash Sinter Process. Light Metals 2011 231-236.

Meher, S.N., Rout, A.K., Padhi, B.K., 2011b. Recovery of Al and Na Values from Red Mud by $\mathrm{BaO}-\mathrm{Na} 2 \mathrm{CO} 3$ Sinter Process. E-Journal of Chemistry 8, 1387-1393.

Menzel, R.G., 1968. Uranium Radium and Thorium Content in Phosphate Rocks and Their Possible Radiation Hazard. J. Agr. Food Chem. 16, 231-234.

Merten, D. and Buchel, G., 2004. Determination of rare earth elements in acid mine drainage by inductively coupled plasma mass spectrometry. Microchim. Acta 148, 163-170.

Meskers, C.E.M., Hageluken, C., Van Damme, G., 2009. Green Recycling of EEE: Special and Precious Metal Recovery from EEE. EPD Congress 2009, 1131-1136.

Morf, L.S., Gloor, R., Haag, O., Haupt, M., Skutan, S., Di Lorenzo, F., Boni, D., 2013. Precious metals and rare earth elements in municipal solid waste - Sources and fate in a Swiss incineration plant. Waste Manage. 33, 634-644. 
Moriwaki, H. and Yamamoto, H., 2013. Interactions of microorganisms with rare earth ions and their utilization for separation and environmental technology. Appl. Microbiol. Biotechnol. 97, 1-8.

Muller, T. and Friedrich, B., 2004. Development of a $\mathrm{CaO}-\mathrm{CaF}_{2}$-slag system for high rare earth contents. Proceedings of 7th International Conference on Molten Slags, Fluxes and Salts, 25-28 January, 2004, Capetown, South Africa 449-454.

Muller, T. and Friedrich, B., 2006. Development of a recycling process for nickel-metal hydride batteries. J. Power Sources 158, 1498-1509.

Muraleedharan, T.R., Philip, L., Iyengar, L., Venkobachar, C., 1994. Application Studies of Biosorption for Monazite Processing-Industry Effluents. Bioresource Technol. 49, 179-186.

Natansohn, S., Rourke, W.J., Lai, W.C., 1992. Recovery of Valuable Metals from IndustrialWastes. ACS Symp. Ser. 509, 129-146.

Nockemann, P., Thijs, B., Pittois, S., Thoen, J., Glorieux, C., Van Hecke, K., Van Meervelt, L., Kirchner, B., Binnemans, K., 2006. Task-Specific Ionic Liquid for Solubilizing Metal Oxides. J. Phys. Chem. B 110, 20978-20992.

O'Connor, B.H., Donoghue, A.M., Manning, T.J.H., Chesson, B.J., 2013. Radiological Assessment for Bauxite Mining and Alumina Refining. Ann. Occup. Hyg. 57, 63-76.

Ochsenkühn-Petropoulou, M., Lyberopulu, T., Ochsenkuhn, K.M., Parissakis, G., 1996. Recovery of lanthanides and yttrium from red mud by selective leaching. Anal. Chim. Acta $319,249-254$. 
Ochsenkühn-Petropoulou, M., Lyberopulu, T., Parissakis, G., 1994. Direct determination of lanthanides, yttrium and scandium in bauxites and red mud from alumina production. Anal. Chim. Acta 296, 305-313.

Ochsenkühn-Petropoulou, M.T., Hatzilyberis, K.S., Mendrinos, L.N., Salmas, C.E., 2002. Pilot-Plant Investigation of the Leaching Process for the Recovery of Scandium from Red Mud. Ind. Eng. Chem. Res. 41, 5794-5801.

Palsson, B.I., Martinsson, O., Wanhainen, C., Fredriksson, A., 2014. Unlocking rare earth elements from european apatite-iron ores. Proceedings of the 1st European Rare Earth Resources Conference (ERES 2014), Milos (Greece), 4-7 September 2014 221-220.

Papastefanou, C., Stoulos, S., Ioannidou, A., Manolopoulou, A., 2006. The application of phosphogypsum in agriculture and the radiological impact. J. Environ. Radioactiv. 89, 188198.

Paramguru, R.K., Rath, P.C., Misra, V.N., 2005. Trends in red mud utilization - A review. Miner. Process. Extr. Metall. Rev. 26, 1-29.

Paridaens, J. and Vanmarcke, H., 2001. Radium contamination of the banks of the river Laak as a consequence of the phosphate industry in Belgium. J. Environ. Radioactiv. 54, 53-60.

Paridaens, J. and Vanmarcke, H., 2008. Radiological impact of almost a century of phosphate industry in Flanders, Belgium. Health Phys. 95, 413-424.

Pasechnik, L.A., Shirokova, A.G., Koryakova, O.V., Sabirzyanov, N.A., Yatsenko, S.P., 2004. Complexing properties of scandium(III) in alkaline medium. Russ. J. Appl. Chem. 77, 1070-1073. 
Patterson, S.H., Kurtz, H.F., Olson, J.C., Neeley, C.L., 1986. World Bauxite Resources. U.S. Geological Survey professional paper;1076-B United States Government Printing Office, Washington

Peters, F.A., Kirby, R.C., Higbie, K.B., 1967. Methods for producing alumina from clay - An evaluation. J. Met. 19, 26-34.

Petrakova, O., Klimentenok, G., Panov, A., Gorbachev, S., 2014. Application of modern methods for red mud processing to produce rare earth elements. Proceedings of the 1st European Rare Earth Resources Conference (ERES 2014), Milos (Greece), 4-7 September $2014221-229$.

Philip, L., Iyengar, L., Venkobachar, C., 2000. Biosorption of U, La, Pr, Nd, Eu and Dy by Pseudomonas aeruginosa. J. Ind. Microbiol. Biotechnol. 25, 1-7.

Piga, L., Pochetti, F., Stoppa, L., 1993. Recovering Metals from Red Mud Generated During Alumina Production. J. Miner. Met. Mater. Soc. 45, 54-59.

Pontikes, Y. and Angelopoulos, G.N., 2013. Bauxite residue in cement and cementitious applications: Current status and a possible way forward. Resour. Conserv. Recy. 73, 53-63.

Power, G., Grafe, M., Klauber, C., 2011. Bauxite residue issues: I. Current management, disposal and storage practices. Hydrometallurgy 108, 33-45.

Preston, J.S., 1996. The recovery of rare earth oxides from a phosphoric acid byproduct .4. The preparation of magnet-grade neodymium oxide from the light rare earth fraction. Hydrometallurgy 42, 151-167. 
Preston, J.S., Cole, P.M., Craig, W.M., Feather, A.M., 1996a. The recovery of rare earth oxides from a phosphoric acid by-product .1. Leaching of rare earth values and recovery of a mixed rare earth oxide by solvent extraction. Hydrometallurgy 41, 1-19.

Preston, J.S., Cole, P.M., Dupreez, A.C., Fox, M.H., Fleming, A.M., 1996b. The recovery of rare earth oxides from a phosphoric acid by-product .2 . The preparation of high-purity cerium dioxide and recovery of a heavy rare earth oxide concentrate. Hydrometallurgy 41, 21-44.

Preston, J.S., Dupreez, A.C., Cole, P.M., Fox, M.H., 1996c. The recovery of rare earth oxides from a phosphoric acid by-product .3. The separation of the middle and light rare earth fractions and the preparation of pure europium oxide. Hydrometallurgy 42, 131-149.

Preston, J.S. and Du, P., 1998. The recovery of a mixed rare-earth oxide and the preparation of cerium, europium and neodymium oxides from a south african phosphoric acid sludge by solvent extraction. Miner. Process. Extr. Metall. Rev. 18, 175-200.

Protano, G. and Riccobono, F., 2002. High contents of rare earth elements (REES) in stream waters of a $\mathrm{Cu}-\mathrm{Pb}-\mathrm{Zn}$ mining area. Environ. Pollut. 117, 499-514.

Pyagai, I.N., Pasechnik, L.A., Yatsenko, A.S., Skachkov, V.M., Yatsenko, S.P., 2012.

Recovery of sludge from alumina production. Russ. J. Appl. Chem. 85, 1649-1653.

Qin, S.O. and Wu, B.L., 2011. Reducing the radiation dose of red mud to environmentally acceptable levels as an example of novel ceramic materials. Green Chem. 13, 2423-2427.

Qu, Y. and Lian, B., 2013. Bioleaching of rare earth and radioactive elements from red mud using Penicillium tricolor RM-10. Bioresource Technol. 136, 16-23.

Querol, X., Fernandezturiel, J.L., Lopezsoler, A., 1995. Trace-Elements in Coal and Their Behavior During Combustion in A Large Power-Station. Fuel 74, 331-343. 
Radhika, S., Kumar, B.N., Kantam, M.L., Reddy, B.R., 2011. Solvent extraction and separation of rare-earths from phosphoric acid solutions with TOPS 99. Hydrometallurgy 110, $50-55$.

Raspopov, N.A., Korneev, V.P., Averin, V.V., Lainer, Yu.A., Zinoveev, D.V., Dyubanov, V.G., 2013. Reduction of iron oxides during the pyrometallurgical processing of red mud. Russ. Metall. 2013, 41-45.

Reddy, B.R., Kumar, B.N., Radhika, S., 2009. Solid-Liquid Extraction of Terbium from Phosphoric Acid Medium using Bifunctional Phosphinic Acid Resin, Tulsion CH-96. Solvent Extr. Ion Exch. 27, 695-711.

Reuter, M.A., Hudson, C., van Schaik, A., Heiskanen, K., Meskers, C., Hageluken, C., 2013. UNEP (2013) Metal Recycling: Opportunities, Limits, Infrastructure, A Report of the Working Group on the Global Metal Flows to the International Resource Panel.

Reuter, M.A. and van Schaik, A., 2013. 10 design for recycling rules, product centric recycling \& urban/landfill mining. Proceedings of the Second International Academic Enhanced Landfill Mining Symposium (14-16 October 2013, Houthalen-Helchteren, Belgium) 103-118.

Rhodia, 2011. Press Release: Umicore and Rhodia develop unique rare earth recycling process for rechargeable batteries.

Richardson, J., 2013. Up to 2,500 per cent higher concentration levels in Ja's red mud: "Godblessed dirt". Jamaica Observer 13 February 2013.

Roig, M.G., Manzano, T., Diaz, M., 1997. Biochemical process for the removal of uranium from acid mine drainages. Water Res. 31, 2073-2083. 
Roosen, J. and Binnemans, K., 2014. Adsorption and chromatographic separation of rare earths with EDTA- and DTPA-functionalized chitosan biopolymers. J. Mater. Chem. A 2, $1530-1540$.

Roosen, J., Spooren, J., Binnemans, K., 2014. Adsorption performance of functionalized chitosan-silica hybrid materials toward rare earths. J. Mater. Chem. A 2, 19415-19426.

Royset, J. and Ryum, N., 2005. Scandium in aluminium alloys. Int. Mater. Rev. 50, 19-44.

Rutherford, P.M., Dudas, M.J., Samek, R.A., 1994. Environmental Impacts of Phosphogypsum. Sci. Total Environ. 149, 1-38.

Ruyters, S., Mertens, J., Vassilieva, E., Dehandschutter, B., Poffijn, A., Smolders, E., 2011. The Red Mud Accident in Ajka (Hungary): Plant Toxicity and Trace Metal Bioavailability in Red Mud Contaminated Soil. Environ. Sci. Technol. 45, 1616-1622.

Samouhos, M., Taxiarchou, M., Tsakiridis, P.E., Potiriadis, K., 2013. Greek "red mud" residue: A study of microwave reductive roasting followed by magnetic separation for a metallic iron recovery process. J. Hazard. Mater. 254, 193-205.

Sanchez-Segado, S., Lahiri, A., Jha, A., 2015. Alkali roasting of bomar ilmenite: rare earths recovery and physico-chemical changes. Open Chem. 13, 270-278.

Sargic, V. and Logomerac, V., 1974. Leaching and extraction in the complex processing of red mud. Travaux ICSOBA 11, 71-78.

Saueia, C.H., Mazzilli, B.P., Favaro, D.I.T., 2005. Natural radioactivity in phosphate rock, phosphogypsum and phosphate fertilizers in Brazil. J. Radioanal. Nucl. Chem. 264, 445-448. 
Sayan, E. and Bayramoglu, M., 2004. Statistical modeling and optimization of ultrasoundassisted sulfuric acid leaching of TiO2 from red mud. Hydrometallurgy 71, 397-401.

Seredin, V.V., 1996. Rare earth element-bearing coals from the Russian Far East deposits. Int. J. Coal Geol. 30, 101-129.

Seredin, V.V. and Dai, S.F., 2012. Coal deposits as potential alternative sources for lanthanides and yttrium. Int. J. Coal Geol. 94, 67-93.

Seredin, V.V., Dai, S.F., Sun, Y.Z., Chekryzhov, I.Y., 2013. Coal deposits as promising sources of rare metals for alternative power and energy-efficient technologies. Appl.

Geochem. 31, 1-11.

Seredin, V.V. and Finkelman, R.B., 2008. Metalliferous coals: A review of the main genetic and geochemical types. Int. J. Coal Geol. 76, 253-289.

Shakhashiro, A., Sansone, U., Wershofen, H., Bollhofer, A., Kim, C.K., Kim, C.S., Korun, M., Moune, M., Lee, S.H., Tarjan, S., 2010. Technically Enhanced Naturally Occurring Radionuclides (TENORM) in Phosphogypsum. Metrologia 47, Art. 06018.

Shlewit, H., 2011. Treatment of phosphate rocks with hydrochloric acid. J. Radioanal. Nucl. Chem. 287, 49-54.

Singh, M., 2002. Treating waste phosphogypsum for cement and plaster manufacture. Cement Concrete Res. 32, 1033-1038.

Singh, M., Garg, M., Rehsi, S.S., 1993. Purifying phosphogypsum for building manufacture. Constr. Build. Mater. 7, 3-7. 
Smirnov, D.I. and Molchanova, T.V., 1997. The investigation of sulphuric acid sorption recovery of scandium and uranium from the red mud of alumina production. Hydrometallurgy $45,249-259$.

Smith, P., 2009. The processing of high silica bauxites - Review of existing and potential processes. Hydrometallurgy 98, 162-176.

Somlai, J., Jobbagy, V., Kovacs, J., Tarjan, S., Kovacs, T., 2008. Radiological aspects of the usability of red mud as building material additive. J. Hazard. Mater. 150, 541-545.

Sushil, S. and Batra, V.S., 2008. Catalytic applications of red mud, an aluminium industry waste: A review. Appl. Catal. B 81, 64-77.

Szamalek, K., Konopka, G., Zglinicki, K., Marciniak-Maliszewska, B., 2013. New potential source of rare earth elements. Gospod. Surowcami Min. 29, 59-76.

Tanaka, M., Oki, T., Koyama, K., Narita, H., and Oishi, T., 2013. Recycling of Rare Earths from Scrap. in: Bünzli, J.-C.G. and Pecharsky, V.K. (Eds.), Handbook on the Physics and Chemistry of Rare Earths, Vol. 43, Chapter 255 Elsevier, Amsterdam, pp. 159-212.

Tang, K., Ciftja, A., van der Eijk, C., Wilson, S., Tranell, G., 2013. Recycling of the Rare Earth Oxides from Spent Rechargeable Batteries Using Waste Metallurgical Slags. J. Min. Metall. Sect. B Metall. 49, 233-236.

Tanutrov, I.N., Sviridova, M.N., Savenya, A.N., 2013. A new technology for coprocessing man-made wastes. Russ. J. Non-Ferr. Met. 54, 136-142.

Tayibi, H., Choura, M., Lopez, F.A., Alguacil, F.J., Lopez-Delgado, A., 2009. Environmental impact and management of phosphogypsum. J. Environ. Manage. 90, 2377-2386. 
Todorovsky, D., Terziev, A., Milanova, M., 1997. Influence of mechanoactivation on rare earths leaching from phosphogypsum. Hydrometallurgy 45, 13-19.

Topel, S.D., Legaria, E.P., Tiseanu, C., Rocha, J., Nedelec, J.M., Kessler, V.G., Seisenbaeva, G.A., 2014. Hybrid silica nanoparticles for sequestration and luminescence detection of trivalent rare-earth ions $\left(\mathrm{Dy}^{3+}\right.$ and $\left.\mathrm{Nd}^{3+}\right)$ in solution. J. Nanopart. Res. 16.

Tsakanika, L.V., Ochsenkühn-Petropoulou, M.T., Mendrinos, L.N., 2004. Investigation of the separation of scandium and rare earth elements from red mud by use of reversed-phase HPLC. Anal. Bioanal. Chem. 379, 796-802.

Tsuruta, T., 2007. Accumulation of rare earth elements in various microorganisms. J. Rare Earths 25, 526-532.

Umicore, 2009. Press release CP-2009-31-R: Umicore invests in recycling of rechargeable batteries.

Umicore, 2011. Press release CP-2011-35: Inauguration of battery recycling facility in Hoboken.

Vanbellen, F. and Chintinne, M., 2006. The precious art of metals recycling. Advanced Processing of Metals and Materials (Sohn International Symposium), Volume 1, Thermo and Physicochemical Principles: Nonferrous High Temperature Processing, 43-52.

Vanderheijde, H.B., Klijn, P.J., Duursma, K., Eisma, D., Degroot, A.J., Hagel, P., Koster, H.W., Nooyen, J.L., 1990. Environmental Aspects of Phosphate Fertilizer Production in the Netherlands - with Particular Reference to the Disposal of Phosphogypsum. Sci. Total Environ. 90, 203-225. 
Verhaeghe, F., Goubin, F., Yazicioglu, B., Schurmans, M., Thijs, B., Haesebroek, G., Tytgat, J., Van Camp, M., 2011. Valorisation of battery recycling slags . Proceedings of the 2nd International Slag Valorisation Symposium (18-20 April 2011, Leuven, Belgium) 365-373.

Wagh, A.S. and Pinnock, W.R., 1987. Occurrence of Scandium and Rare-Earth Elements in Jamaican Bauxite Waste. Econ. Geol. 82, 757-761.

Wang, L.S., Long, Z.Q., Huang, X.W., Yu, Y., Cui, D.L., Zhang, G.C., 2010. Recovery of rare earths from wet-process phosphoric acid. Hydrometallurgy 101, 41-47.

Wang, L.S., Yu, Y., Liu, Y., Long, Z.Q., 2011a. Centrifugal extraction of rare earths from wet-process phosphoric acid. Rare Metals 30, 211-215.

Wang, W.W., Pranolo, Y., Cheng, C.Y., 2011b. Metallurgical processes for scandium recovery from various resources: A review. Hydrometallurgy 108, 100-108.

Wang, W.W., Pranolo, Y., Cheng, C.Y., 2013. Recovery of scandium from synthetic red mud leach solutions by solvent extraction with D2EHPA. Sep. Purif. Technol. 108, 96-102.

Werner, G., Giseke, H., Holzapfe, H., 1966a. Untersuchungen Uber Die Extraktion der Seltenen Erden Mit Tributylphosphat .2. Seltenerd-Gewinnung aus Kola-Apatit. J. LessCommon Met. 11, 209-215.

Werner, G., Pritzkow, J., Wildner, O., Holzapfe, H., 1966b. Untersuchungen Uber Die Extraktion der Seltenen Erden Mit Tributylphosphat .I. Die Extraktion aus Calciumphosphathaltiger Losung. J. Less-Common Met. 10, 323-327.

Xenidis, A., Zografidis, C., Kotsis, I., Boufounos, D., 2009. Reductive Roasting and Magnetic Separation of Greek Bauxite Residue for Its Utilization in Iron Ore Industry. Light Metals 2009 63-67. 
Xenidis, A., Zografidis, C., Kotsis, I., Boufounos, D., 2011. Reductive Smelting of Greek Bauxite Residues for Iron Production. Light Metals 2011 113-117.

Xie, F., Zhang, T.A., Dreisinger, D., Doyle, F., 2014. A critical review on solvent extraction of rare earths from aqueous solutions. Miner. Eng. 56, 10-28.

Xu, S.Q. and Li, S.Q., 1996. Review of the extractive metallurgy of scandium in China (19781991). Hydrometallurgy 42, 337-343.

Xu, T. and Peng, H.Q., 2009. Formation cause, composition analysis and comprehensive utilization of rare earth solid wastes. J. Rare Earths 27, 1096-1102.

Yang, H.L., Wang, W., Zhang, D.L., Deng, Y.F., Cui, H.M., Chen, J., Li, D.Q., 2010.

Recovery of Trace Rare Earths from High-Level $\mathrm{Fe}^{3+}$ and $\mathrm{Al}^{3+}$ Waste of Oil Shale Ash (FeAl-OSA). Ind. Eng. Chem. Res. 49, 11645-11651.

Yang, X.H., Long, H., Cheng, G.G., Wu, C.C., Wu, B., 2011. Effect of refining slag containing $\mathrm{Ce}_{2} \mathrm{O}_{3}$ on steel cleanliness. J. Rare Earths 29, 1079-1083.

Yantasee, W., Fryxell, G.E., Addleman, R.S., Wiacek, R.J., Koonsiripaiboon, V., Pattamakomsan, K., Sukwarotwat, V., Xu, J., Raymond, K.N., 2009. Selective removal of lanthanides from natural waters, acidic streams and dialysate. J. Hazard. Mater. 168, 12331238.

Yatsenko, S.P. and Pyagai, I.N., 2010. Red mud pulp carbonization with scandium extraction during alumina production. Theor. Found. Chem. Eng. 44, 563-568.

Yatsenko, S.P., Sabirzyanov, N.A., Pasechnik, L.A., Rubinshteyn, G.M., Diev, V.N., Skryabneva, L.M., 2005. Multiple-stage leaching of red mud for recovery of scandium oxide. Russian Patent RU2247788 
Yu, X.L., Bai, L., Wang, Q.C., Liu, J., Chi, M.Y., Wang, Z.C., 2012. Recovery of Rare Earths, Niobium, and Thorium from the Tailings of Giant Bayan Obo Ore in China. Metall. Mater. Trans. B 43, 485-493.

Zaman, A.U., 2014. Identification of key assessment indicators of the zero waste management systems. Ecol. Indic. 36, 682-693.

Zaman, A.U. and Lehmann, S., 2013. The zero waste index: a performance measurement tool for waste management systems in a 'zero waste city'. J. Clean. Prod. 50, 123-132.

Zazubin, A.I., Barshchevskaya, A.N., Potapova, G.M., 1967. Complex reprocessing of red mud. Tr. Inst. Metall. Obogashch., Akad. Nauk Kaz. SSR 25, 3-7.

Zhang, B., Liu, C.J., Li, C.L., Jiang, M.F., 2014. A novel approach for recovery of rare earths and niobium from Bayan Obo tailings. Miner. Eng. 65, 17-23.

Zhao, L.J., Zhang, F.S., Zhang, J.X., 2008. Chemical properties of rare earth elements in typical medical waste incinerator ashes in China. J. Hazard. Mater. 158, 465-470.

Zhao, T.A., Li, B.W., Gao, Z.Y., Chang, D.Q., 2010. The utilization of rare earth tailing for the production of glass-ceramics. Mater. Sci. Eng. B 170, 22-25.

Zheng, X.P. and Lin, H.K., 1994. Mineralogy and Flotation of Rare-Earth-Bearing Barium Fluorophlogopite. Miner. Eng. 7, 1495-1503.

Zielinski, R.A., Al-Hwaiti, M.S., Budahn, J.R., Ranville, J.F., 2011. Radionuclides, trace elements, and radium residence in phosphogypsum of Jordan. Environ. Geochem. Health 33, $149-165$. 
Zielinski, S., Szczepanik, A., Buca, M., Kunecki, M., 1993. Recovery of Lanthanides from Kola Apatite in Phosphoric-Acid Manufacture. J. Chem. Technol. Biot. 56, 355-360.

ZWIA, 2004. Zero Waste Definition Adopted by Zero Waste Planning Group [Online]. 